\title{
Boundary layer physics over snow and ice
}

\author{
P. S. Anderson ${ }^{1, *}$ and W. D. Neff ${ }^{2}$ \\ ${ }^{1}$ British Antarctic Survey, Cambridge, UK \\ ${ }^{2}$ NOAA Earth System Research Laboratory, Boulder, CO, USA
}

Received: 20 April 2007 - Published in Atmos. Chem. Phys. Discuss.: 4 June 2007

Revised: 22 April 2008 - Accepted: 18 May 2008 - Published: 7 July 2008

\begin{abstract}
Observations of the unique chemical environment over snow and ice in recent decades, particularly in the polar regions, have stimulated increasing interest in the boundary layer processes that mediate exchanges between the ice/snow interface and the atmosphere. This paper provides a review of the underlying concepts and examples from recent field studies in polar boundary layer meteorology, which will generally apply to atmospheric flow over snow and ice surfaces. It forms a companion paper to the chemistry review papers in this special issue of ACP that focus on processes linking halogens to the depletion of boundary layer ozone in coastal environments, mercury transport and deposition, snow photochemistry, and related snow physics. In this context, observational approaches, stable boundary layer behavior, the effects of a weak or absent diurnal cycle, and transport and mixing over the heterogeneous surfaces characteristic of coastal ocean environments are of particular relevance.
\end{abstract}

\section{Introduction}

A variety of processes near the surface of the Earth mediate the transfer of heat, momentum, moisture, and chemical species between the surface and the overlying atmosphere. As a number of studies over the last decade in the polar regions have shown, these processes include a complex mixture of both turbulent boundary layer exchange and horizontal transport. A number of studies, motivated by the early observation of ozone-depleting episodes (ODEs) in the Arctic, have taken place in the coastal margins of both the Arctic and the Antarctic where sea ice, open water, snow-covered coastal margins and abrupt topographic features create a highly heterogeneous environment. These studies contrast

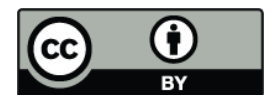

Correspondence to: P. S. Anderson (philip.s.anderson@bas.ac.uk) with those over the nearly homogeneous ice surfaces characterizing the interior of Antarctica and Greenland where snow photochemistry has been the primary interest.

This paper grew out of a request from the Air-Ice Chemical Interactions (AICI) community for a paper on the physics of the boundary layer to supplement the state-of-the-science papers in this special issue addressing snow photochemistry, halogens and ozone-depleting episodes, and mercury transport and deposition in the polar regions. Such a discussion is warranted due to the interplay of physical mechanisms that may affect trace gas measurements made near the surface, especially when the surface is, itself, a source of trace gas or catalytic to reaction. An additional motivation are recent surprises such as 1) the unexpectedly high levels of nitric oxide found over the high interior of Antarctic that appear to have origins in the formation of very shallow mixing layers coupled with photo-denitrification of the snow and 2) the complex chemistry and meteorology of the more deeply mixed ozone-deleting-episodes (ODEs) found first in the Arctic and more recently in the Antarctic. This paper is intended to serve as an introduction to the most relevant boundary layer physics and meteorology applicable to such chemical phenomena, including suitable techniques for observing and quantifying the related atmospheric processes.

A number of field programs have contributed to our understanding of boundary layer physical processes and their relevance to boundary layer air chemistry and snow/ice-air chemical interactions in polar regions. Several of note are:

- Neumayer: Variations in $\mathrm{NO}_{\mathrm{x}}$ gradients derived from PEAN'99 data (Photochemical Experiment at Neumayer) were correlated with estimates of actinic flux once boundary layer activity (mixing) was considered Jones et al. (2001). Although limited micrometeorological data were available, turbulent diffusivity and actinic flux were inferred from standard meteorological data, indicating the role of turbulence in air

Published by Copernicus Publications on behalf of the European Geosciences Union. 
chemistry near the ground. A similar study for Peroxyacetyl nitrate (PAN) during PEAN'99 highlighted the benefits of having co-located in situ turbulence sensors during boundary layer chemistry campaigns (Jacobi et al., 2000).

- Halley: The main air chemistry facility at Halley, the Clean Air Sector Laboratory (CASLab) deployed in the $2002 / 3$ austral summer, is co-located with a range of turbulence and profile instrumentation within the Instrumented Clean Air Sector (ICAS). Micro-meteorology support data are available from a 30-m vertical array of sonic anemometers, propeller vane and aspirated temperature sensors, sodar and microbarograph array (see Sect. 5 for a detailed discussion of boundary layer instrumentation). Results from these facilities are reported elsewhere, (Jones et al., 2008), but especial note should be taken of Jones et al. (2006) describing the dependence of near surface ozone upon mixing or frontal events.

- Amundsen-Scott South Pole Station: During the Investigation of Sulfur Chemistry in the Antarctic Troposphere (ISCAT) project at the South Pole in 1998, unexpectedly high near-surface concentrations of nitric oxide, (NO), were found and linked to photodenitrification of the snow and subsequent flux of NO into the boundary layer (Davis et al., 2001). A subsequent study in the spring of 2000 suggested that the extremely high (NO) could be explained by a combination of factors including non-linear chemical processes, shallow boundary layers, and $\mathrm{NO}_{\mathrm{x}}$ accumulation in air parcels as they drain off the high plateau toward the South Pole (Davis et al., 2004b). However, these earlier studies lacked documentation of the vertical structure of the boundary layer and associated chemical constituents. These were addressed in a third study in 2003, namely, the Antarctic Tropospheric Chemistry Investigation (ANTCI). Results now include a detailed analysis of boundary layer behaviour and depth using a sodar, tower meteorology, tethered balloon for meteorological profiling, and a sonic anemometer (Neff et al., 2008), tethered balloon profiling of (NO) and $\mathrm{O}_{3}$ (Helmig et al., 2008a, 2008b; Neff, 1978), and numerical modeling that included simulation of boundary layer depth and chemical interactions (Wang et al., 2008). Comparison of observations of mixing layer depth, (NO), and numerical simulations suggested the need for better documentation of snow nitrate levels and the processes controlling the flux of NO from the snow. In addition, analysis of aerosol ions and trace elements suggest significant marine influences during some of the high (NO) episodes at the South Pole (Arimoto et al., 2008) which raises the issue that in remote areas, we have no documentation of the boundary layer processes that occur along these extensive over-the-ice transport trajectories (Neff et al., 2008).

- Coastal Arctic. Following the early discovery of ozone depleting episodes (ODEs) in the arctic (Oltmans, 1981) a number of field programs have exposed the many roles of the complex chemistry and boundary-layer meteorology in the arctic as reviewed in this special issue (Shepson et al., 2003). Unlike the interior of Antarctica where shallow boundary layers dominate atmosphereice chemical interactions, deep mixing from wide leads, up to $4 \mathrm{~km}$ has been found (Schnell et al., 1989). Even modest leads produce mixing to $1 \mathrm{~km}$, the nominal depth of the arctic temperature inversion (Serreze et al., 1992; Kahl, 1990). The depth of the ODEs has been found to be highly variable as revealed in sequential ozonesonde soundings (Shepson et al., 2003; Tarasick and Bottenheim, 2002), reflecting both boundary layer mixing and transport, potentially from the marginal ice zone, over periods of one to three days ....(Bottenheim and Chan, 2006).

- GEOSummit, Greenland. Following the successful GISP2 and GRIP ice core drilling campaigns of the 1990's, the Greenland Environmental Observatory at Summit, (GEOSummit) now hosts multi-disciplinary environmental science with a history of air chemistry and air-snow interaction studies, (Dibb et al., 2007; Dibb and Jaffrezo, 1997), boundary layer physics (Drue and Heinemann, 2007; Cullen et al., 2007; Hoch et al., 2007; Forrer and Rotach, 1997; Cullen and Steffen, 2001) and more recently, combined studies (Cohen et al., 2007; Helmig et al., 2002).

- Dome C, Antarctica. As for GEOSummit, the need for interpretation of the EPICA ice core samples from Dome C initiated combined air chemistry and boundary layer physics campaigns at the site. Although both the level of instrumentation and subsequent publication is as yet sparse (Udisti et al., 2004) compared to GEOSummit, the site, at a altitude of $75^{\circ} \mathrm{S}$ and an altitude of $3233 \mathrm{~m}$ is comparable to GEOSummit.at $72^{\circ} \mathrm{N}$ and an altitude of $3250 \mathrm{~m}$. The radiative forcing at the top of the atmosphere will be very similar at the two sites, and differences observed at the surface will be of great interest to both the chemistry and physics communities.

This list is not intended as an exhaustive review of boundary layer air chemistry studies, but indicates where interdisciplinary physics and air chemistry field campaigns have enhanced the understanding of boundary layer processes in both discipline areas.

Section 2 provides specific and practical definitions of the Atmospheric Boundary Layer, and introduces the concept of mixing height. Section 3 summarizes the mechanisms where variation in boundary layer characteristics will affect 
air chemistry studies, either by modifying the chemistry itself, of by generating extrinsic signals in sample measurements. Section 4 describes the main general types of boundary layer encountered in polar field work, based on stratification and topography. It should be noted that this section depends significantly on conceptual advances produced by the deployment in past field campaigns of both remote sensors, primarily acoustic sounders (known as sodars), optical profiling, and in-situ turbulence measurements. Sodars have proven particularly useful in Antarctic field programs because they work well in harsh environments and remotely profile thermal turbulence with high resolution vertically and with time, helping conceptualize boundary layer behavior that affects air chemistry near the snow and ice surfaces. Section 5 describes the range of micro-meteorological field equipment that has been deployed in a variety of boundary layer field programs,. Section 6 summarizes the issues presented. Appendix I is a list of useful equations.

\section{Defining the boundary layer}

(Stull, 1988) defines the atmospheric boundary layer as "that part of the atmosphere that is directly influenced by the presence of the earth's surface, and responds to surface forcing with a time scale of an hour or less." Such forcing includes processes affecting the transfer of heat, momentum and moisture, the effect of terrain variations, as well as emissions of trace gases that affect the radiative balance at the surface and within the air. In the polar regions, the response to surface forcing may be much slower than an hour under very stable conditions (Neff et al., 2008) and the Earth's rotation may play a larger role because the inertial period approaches twelve hours at the poles. For air chemistry modeling studies the most significant physical boundary layer variables are height, $h_{z}$, and the profile of the diffusivity, $K(z)$. $h_{z}$ indicates the depth of the reactive mixing region, whilst $K(z)$ quantifies the vertical flux of tracer when multiplied by a known concentration, $C(z)$. Box models of boundary layer air chemistry assume that all chemical species are well mixed through a depth $h_{z}$. On the other hand, one dimensional (1-D) numerical vertical exchange models require $K(z), h_{z}$ being implicit in the $K(z)$ profile. This paper gives added weight to discussion of these two parameters.

\subsection{History and formal definitions}

One of the earliest concepts of a fluid boundary layer was initially proposed by Prandtl (1905) to explain the behaviour of laminar fluid flow tangential to a surface. He noted that if fluid flows past a solid object without slipping, there should be both a very large tangential velocity gradient, $\mathrm{d} u / \mathrm{d} z$, and also large negative velocity curvature, $-\mathrm{d}^{2} u / \mathrm{d} z^{2}$. Diffusive theory could then be applied to this curvature, the resulting implications being that, in steady state, a horizontal decreas- ing pressure gradient, $-\mathrm{d} P / \mathrm{d} x$, must exist to balance this curvature. If the pressure gradient is reduced at any point, for instance by expanding the flow rapidly in a venturi, the boundary layer will separate from the surface. This is the reason why flows are changed gradually over wings or fan blades to prevent such a separation.

Of more relevance to the topic of air chemistry was a secondary conclusion. The depth of the (molecular) boundary layer increases with distance from the "start". Prandtl worked mainly with pipes or flat plates in tanks. The start of the boundary layer was known, and the length of the layer was finite. However, Prandtl's analysis indicated that the boundary layer depth would grow indefinitely. There is no inherent (molecular) boundary layer depth which depends on the local flow characteristics, it depends on distance downstream.

Prandtl's analysis only applies to fluids when the Reynolds Number, $R e$ is small. $R e$ is defined in terms of the kinematic viscosity, $v$, velocity, $V$, and a length scale of the object, $L$, e.g. the diameter of a pipe through which the fluid flows. $R e$ is the dimensionless ratio of these three factors:

$R e=\frac{L V}{v}$

For $R e<600$ the flow will be laminar. However, typical $R e$ for atmospheric flows are of order $10^{5}$ or more and the concept of diffusivity has to be extended to include an equivalent viscosity that represents turbulent exchange of fluid parcels rather than molecular transfer as we will describe in more detail later. However, many aspects of viscous boundary layers carry over in the conceptualization of turbulent boundary layers.

\subsection{Practical and informal definitions}

The literature addressing the depth of boundary layers under conditions of small $R e$ is extensive and the problem is often amenable to analytical solution. However, the definition of the boundary layer depth under realistic atmospheric conditions is problematic because the magnitude and nature of the "turbulent diffusivity" responds to intrinsic properties of the flow such as wind shear and vertical temperature differences. In addition, within a stably stratified atmosphere (one where the effect of buoyancy acts to restore a displaced air parcel back to its original position) wave motions can propagate momentum indirectly and direct turbulent transfer can be extremely weak. Furthermore, the history of the flow upstream of an observation site can determine the properties of the boundary layer at the site rather than the surface forcing at the site itself. Such non-local effects confound parameterization methods based on the local meteorological conditions. For example, flow over leads or polynyas, openings in the ice overlying the ocean, can be modified dramatically by the local heat input (Serreze et al., 1992). On longer time scales $(\sim 12 \mathrm{~h})$, the rotation of the Earth will modify the behaviour 


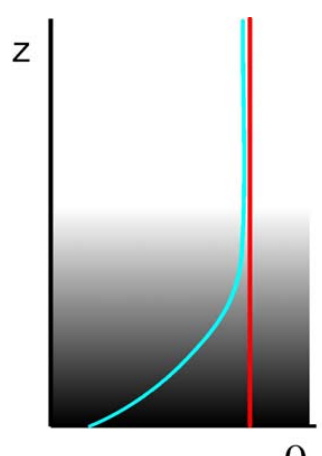

$\theta$
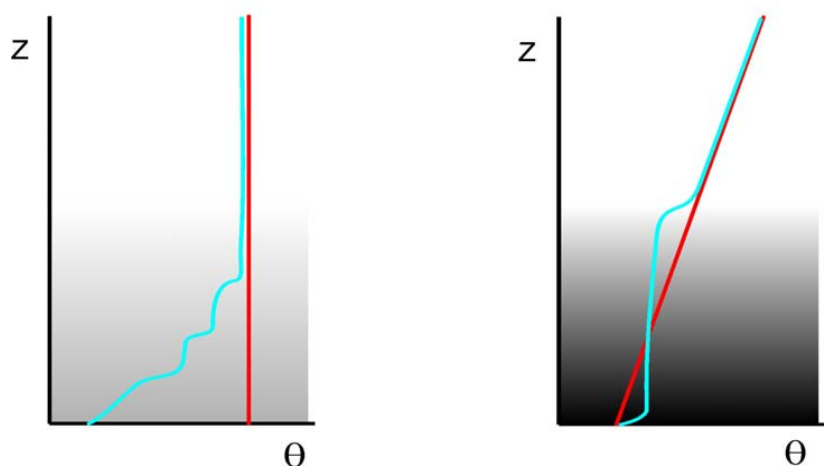

Fig. 1. Idealised initial temperature profiles (red) and their evolution (blue) within different boundary layer types. (a) Isothermal layer being cooled from below. (b) stable layer being mixed by convection, (c) isothermal layer with rapid cooling leading to complex structure and d) "polynyal"; re-cooling of a stable layer following a convective episode.

of turbulent boundary layers, an effect first describe in detail by Ekman (1905).

One of the most conceptually simple definitions of the boundary layer depth is the height at which turbulence decreases to a very small value, typically $10 \%$ of its value at the surface. However, even if a definition based on mixing is valid, measuring mixing in situ above the height of a typical mast $(30 \mathrm{~m})$ is rarely viable. In place of direct measurements, other proxies are often used, the most popular being inspection of the temperature profile (gained from free flying or tethered balloon sondes). However, the temperature profile can be influenced by larger scale weather processes and the history of mixing upstream. Thus, the actual boundary layer may extend through only a small fraction of the depth deduced from the temperature profile, especially under stable conditions. In particular, the temperature profile can reflect a number of mixing processes. For instance, where initially a linear thermal gradient exists, rapid mixing will generate a volume of equalised (potential) temperature, with a sudden step at the edges, as shown in Fig. 1, upper right. Conversely, surface cooling of an initially isothermal boundary layer will

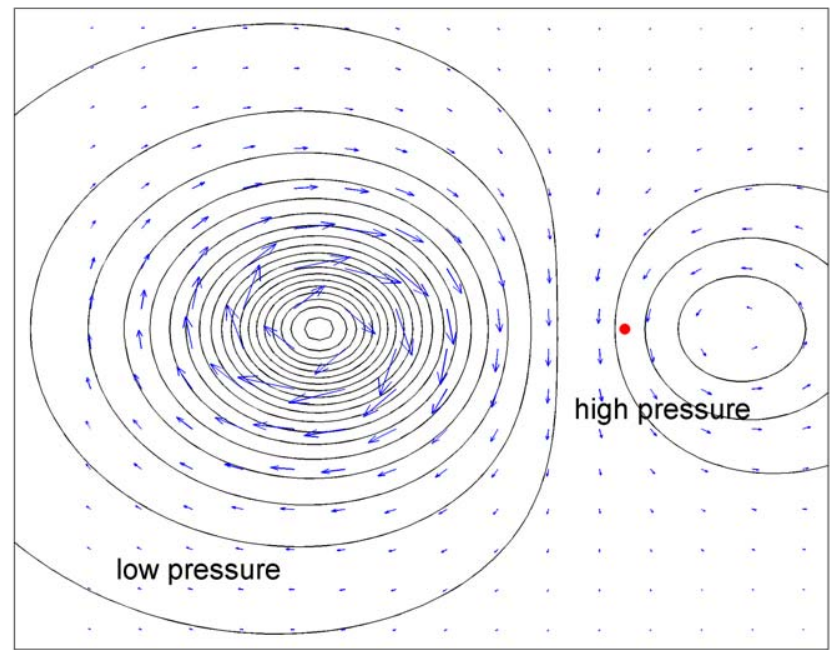

Fig. 2. Idealised synoptic flow as viewed from above, indicating possible sensitivity of back trajectory calculations to small changes in the synoptic wind field. The red dot is a possible sample position which would be exposed to a different air mass should the pressure systems shift slightly to the right, with no associated significant change in wind direction. NB, flow is for Southern Hemisphere.

generate a temperature gradient (Fig. 1, upper left). The ease of measuring temperature gradients has biased the literature to defining the boundary layer according to the profile, and detracts from the fact that the temperature is only a proxy for mixing under limited circumstances such as in the case of convection with a stable layer aloft (Fig. 1b).

This is of notable concern within the polar studies of the physics and chemistry of boundary layers because the bulk of boundary layer literature is based on mid-latitude data, where diurnal variations in insolation dominate the evolution of the boundary layer. Such variation may be absent or minimal in polar regions, whilst other forcing, e.g. drainage (katabatic) forcing or polynyal convection may dominate. The overuse of the term "inversion depth", "top of inversion" and "capping inversion" as identifying the top of the mixing layer may lead to incorrect conclusions regarding the depth, as well as confusing the issue as to the mechanism constraining the mixing height.

\subsection{Mixing depth or boundary layer height}

For integrated chemistry-boundary-layer studies, knowing the mixing depth is often central to understanding the resulting concentrations of tracers, especially for gases released at the surface. For physical studies, $h_{z}$ is a useful scaling function for estimating fluxes of momentum and heat. The lack of universal parameterisation schemes for estimating $h_{z}$ from local meteorological variables is therefore unfortunate, and there is still active research in this subject. Ideal, simplistic models such as (Prandtl, 1905), indicate that the boundary layer grows indefinitely with fetch, clearly an 
unrealistic assumption over virtually infinite plains. Ekman's model limits vertical extent by incorporating the Coriolis parameter (which limits vertical mixing at the inertial period: $12 \mathrm{hrs}$ at the poles) whilst convection and stable stratification incorporate buoyancy (positive and negative respectively) to scale $h_{z}$. In general, however, there is poor correlation between models and measurements.

Figure 1 demonstrates the difficulty in attempts to make estimates of $h_{z}$ from local measurements. In the classic mid-latitude nocturnal stable boundary layer which occurs on cloud free nights, radiative cooling of the surface leads to the development of a vertical potential temperature gradient (Fig. 1a). Figure 1b represents the "early morning" boundary layer, where weak convection from the heated surface mixes out these near-surface temperature differences, but has yet to penetrate fully into the warmer overlying layer. Both of these profiles are observed in polar regions, but occasionally result from different mechanisms. For example, the nocturnal boundary layer profile can be formed by warm air overlying a cold surface, but in polar regions this can frequently occur due to the advection of warm air, not the cooling of the surface. The mid-morning profile in the form of Fig. 1d) is common in polar regions, for instance within or near sea-ice due to polynyal fossil convection, as described in Culf (1989) and Anderson (2003) or when cold air advects over a previously warmed surface. For instance, compare Fig. 1 to the temperature profiles from Eureka, Resolute and Churchill in Tarasick and Bottenheim (2002), the Churchill profile is reproduced here in Fig. 2

Even if we were able to measure the diffusivity at all heights, some inversion/boundary layers evolve complex vertical structure. For reasons still not understood, prolonged surface cooling can result in horizontal layers of turbulence within an otherwise laminar flow. The layers generally evolve from a classic well defined boundary layer, with layers within the turbulent zone becoming laminar. In these situations the turbulent layer in contact with the surface is the most relevant to surface chemical exchange. Unknown at present is the role of the complex turbulent-laminar structures in isolating and spreading chemical species aloft.

Despite the uncertainty in models and measurements of $h_{z}$, there is some consolation for air chemistry studies, in that for modeling work beyond the box model, it is the diffusivity near the surface that is of most interest, and this can be more easily determined, whether by direct measurement, or via proxies (Anderson and Bauguitte, 2006).

\section{How the atmospheric boundary layer (ABL) affects air chemistry observations}

Micro-meteorological mechanisms affecting trace gas observations fall into two broad categories: vertical mixing and horizontal transport. Mixing is the most apparent charac-

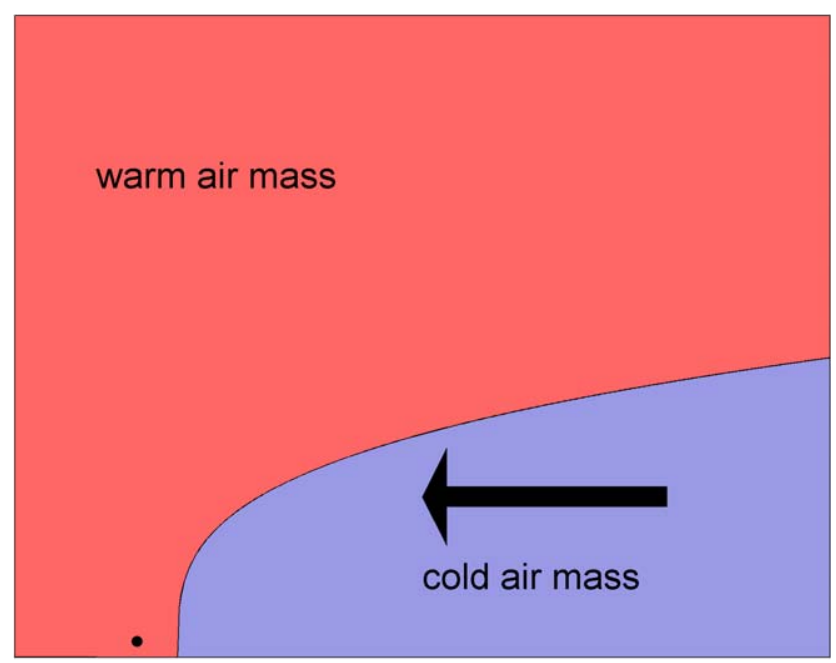

Fig. 3. Schematic of a frontal or bore system seen from the side. As the colder air slowly passes over the field site (small dot), very rapid changes in the tracer signature may be observed.

teristic, whilst transport, or advection, can be all too easily disregarded when observations are made at only one point.

\subsection{Horizontal transport: advection}

Under all but calm wind conditions, boundary layer winds have a net horizontal component, which can have both an actual and an apparent effect on trace gas observations. An example of an apparent effect is when the boundary between two air masses passes over the sampling site. Figure 3 shows an idealised 2-D flow field, viewed from above, of two rotating air masses; the sampling point is slightly off centre. Small relative changes in the positions of the sample site to the air masses movements may cause the sampler to cross the boundary between the air masses, with no significant change in wind speed or direction. If the two air masses have different chemical signatures, the sampling point would observe a rapid change in air composition. This is assumed to be the mechanism underlying some of the observed very rapid Ozone Depletion Events with no associated change in wind direction, such as described in (Bottenheim and Chan, 2006) in Alaska and (Jones et al., 2006) in Antarctica. The recent technique of using reanalysis back trajectories that has highlighted how the source area (and altitude) can rapidly evolve with no apparent local changes in wind pattern (work in progress: Jones et al., 2008). It is clear, however, that such observed changes in concentrations do not necessarily result from chemical reactions. However, mixing across the boundary between the air masses may generate real chemical interaction by bringing together otherwise separated reactive gases, and one might expect the products to show a peak in concentration of the products at the boundary.

Air masses are never as simple as implied by Fig. 3, being invariably three dimensional in structure and evolving in 

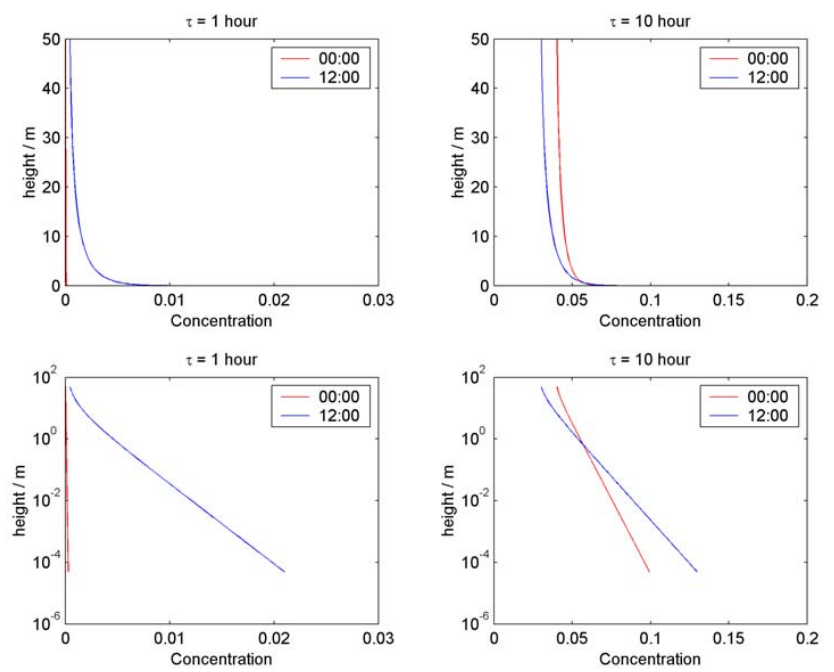

Fig. 4. Profiles of diffusion model concentration at midnight and midday for different values of loss term, $\tau$ and with diurnal variation in tracer flux at the surface The profiles are plotted with both linear and $\log$ height axes. Note the change in scale for the concentration for the different values of $\tau$.

time. Stable air masses typically meet not at vertical boundaries, but with slopes dependent upon density and to some extent upon the relative velocity of the boundary with the surface. The horizontal scale of such boundaries or "fronts" can range from hundreds of kilometres for synoptic scale systems, to a few hundred metres for small scale drainage flows or "bores". In polar regions, where cooled air masses develop frequently, small scale bores may be ubiquitous even within the otherwise homogenous boundary layers that form over ice shelves. Katabatic flow may be regarded as a continuous micro-front, transporting air from upstream underneath "local air". Over sea-ice, where variability in ice thickness, albedo and ice-coverage will lead to "thermal winds", effectively a drainage mechanism over a flat terrain caused by horizontal differences in air density.

The sudden change in air mass associated with such a bore is shown schematically in Fig. 4; sampling of such a flow may result in the vary rapid time series variability, as seen in (Jones et al., 2006) where the micro-frontal system is observed in sodar backscatter images.

\subsection{Vertical mixing}

Mixing through the action of buoyancy- or shear-driven turbulence lies at the heart of boundary layer processes. Although turbulence will be roughly isotropic at small scales, gradients of scalars such as trace gases will usually be largest in the vertical direction, and hence transport along these gradients is predominantly towards or away from the surface.

\subsubsection{Flux vs concentration}

The study of any particular air chemistry species invariably starts with a time series of species concentration at a fixed height. The simplest representation of the time evolution of concentration, in absence of chemical production/loss terms) is given by the following prognostic equation:

$\frac{d C}{d t}=u \cdot \nabla C+\frac{\partial F}{\partial z}$

This states that the change in concentration is the sum of the advective term and the flux divergence. The advective term encompasses a change in concentration, $(\nabla C)$, in space being transported past the sample inlet by the wind, $u$. The vertical flux divergence causes an actual increase or decrease at some level. If the trace gas data available are limited to a single time series at one level, there is insufficient information to estimate the relative magnitude between advection and divergence in even this simplest of representations.

Most real air chemistry observations will involve reactive species, and hence there are additional loss/gain terms. Only by assuming horizontal homogeneity in $C$, such as may exist over a large physically homogenous ice shelf or ice cap, can $\nabla C$ be assumed small. In Anderson and Bauguitte (2006) this assumption allowed the loss terms to be estimated, by measuring $\mathrm{d} C / \mathrm{d} t$ and estimating the flux using turbulence proxies (see below: Sect. 4.1: the neutral boundary layer).

To avoid the need to assume homogeneity, or to estimate better the loss terms for active tracers, the actual flux divergence should be measured, by making co-temporal measurements of concentration at two different heights, in conjunction with a measure of mixing efficiency. The flux is then given by:

$F=K \frac{\partial C}{\partial z}$

$K$ is the diffusivity, a measure of the efficiency of the turbulent mixing. This equation may be understood in two ways.

- For a given flux ( $F$ known), increasing the mixing will reduce the concentration gradient.

- For a given gradient, ( $\partial C / \partial z$ known $)$, increasing the diffusivity increases the flux.

Both of these concepts should be born in mind when designing trace gas flux measurements; for an expected flux, e.g. photogenic $\mathrm{NO}_{\mathrm{x}}$, the largest "signal" to give $\partial C / \partial z$ will occur on days when $K$ is small. Conversely, simply stating $\partial C \backslash \partial z$ data does not give any indication as to the fluxes, as $K$ is also time dependent. $K$ can be measured directly using sonic anemometry, (Neff et al., 2008) or estimated (Jones et al., 2001; Saiz-Lopez et al., 2008). Future developments applying fast response flux measurements in the polar regions may combine sonic anemometry (see Sect. 5.4) and fast response chemical sensors similar to what has been done at 
mid-latitudes (Turnipseed et al., 2006) although a number of challenges remain, particularly under light wind, very stable conditions.

\subsubsection{Variable diffusivity with height, $K(z)$}

Although mixing within the boundary layer is highly efficient, as discussed more fully below, the efficiency reduces as the surface is approached, eventually falling to molecular diffusive efficiencies at the ground. This variable diffusivity will tend to generate, in steady state, log-linear profiles of $C(z)$ near the surface when there is a flux of $C$ in the vertical. More generally, a typical profile of $K(z)$ will show an increase with height to some point within the boundary layer and then decrease to zero at the top, where turbulence decreases to zero (Stull, 1988).

\subsubsection{Surface (and sub-surface) contact}

Mixing occurs within the boundary layer, intermingling parcels of air from different places. Mixing also occurs at the surface in that air parcels, which make fleeting intimate contact with the ground, then mingle with overlying air. Knowledge of the efficiency of this surface contact is needed to understand, say, the importance of the catalytic effect of ice on the reactions. In the case of a porous snow or firn layer, this surface contact may be vastly enhanced by two processes

\section{- Drifting or blowing snow}

- Wave and wind pumping

Drifting and blowing snow has an effective surface are many orders of magnitude greater than a simple surface. Not only is the true surface in contact with the turbulent air all the greater, but the ice particles are better aspirated by continually falling through the air, and being subject to alternating air velocities. This enhanced aspiration significantly enhances the rate at which the boundary layer tends to a saturated equilibrium with the surface. The similarity of processes that govern the adsorbtion of moisture and other trace gases would suggest that evaporation parameters within current blowing snow models may be used as a useful proxy for more complex trace gas exchange in blowing snow. Suitable schemes have been presented by Mann et al. (2000) and Bowling et al. (2004). Further, the validation studies from such parameterisation schemes for moisture (e.g (Mann et al., 2000; Pomeroy and Essery, 1999) may well give insight into the behaviour of surface adsorbing tracers in turbulent flow.

Air-surface interaction is also enhanced by flow across the boundary facilitated by the porosity of the snow or firn in conjunction with surface micro-pressure field fluctuations. Short term $(\sim 10 \mathrm{~s})$ variation in the mean surface pressure are generated by three main processes:
- Dynamic pressure fluctuations, due to flow distortion around surface features such as sastrugi (Albert, 2002; Albert et al., 2002)

- Atmospheric Internal Gravity Waves (IGWs)(Anderson et al., 1992)

\section{- Atmospheric Turbulence}

Variability within the surface pressure field is mirrored by atmospheric pressure gradients within the porous firn, which in turn drives Darcy type flow. Curvature in these gradients leads to divergence, and thence surface ventilation (Albert, 2002; Albert et al., 2002; Cunningham and Waddington, 1993; Neumann and Waddington, 2004). Larger scale firn ventilation, e.g. from large sastrugi or IGWs, will act not only as an enhancement to surface interaction, but also enhance tracer exchange at depth. The climatological scale of such wave-generated deep flow has yet to be measured directly, but may be inferred from microbarograph time signatures.

\section{Boundary layer types}

The large scale structure of the boundary layer, and the subsequent efficiency for vertical mixing, depends primarily on the wind speed and the temperature structure. For certain cases there are additional constraints, such as the local slope of the surface or flow effects arising from up-wind topographic features. To organize the discussion, we will describe the following broad boundary layer types:

- Neutral

- Convective

- Moderately stable over flat terrain

- Moderately stable over sloping terrain

Two other significant and identifiable "types" of polar boundary layer are the polynyal or Marginal Ice Zone (MIZ) boundary layer, and the complex stable boundary layer. The polynyal boundary layer occurs when cold, stable air advects over warm open sea water, usually within sea-ice. Whereas the polynyal boundary layer involves an atmospheric response to a localized heat input, the MIZ boundary layer reflects a transition boundary layer whose characteristics would depend on the wind direction: flow from open water onto ice or vice-versa. The complex stable boundary layer occurs when stratification is sufficiently strong and winds light enough to locally suppress wind-shear generated turbulence; this type occurs over flat terrain such as ice shelves, closed pack-ice, and even over the high sloping plateaus of Greenland and Antarctica. Both types are of major interest to the polar air chemistry community, but their additional complexity and lack of suitable universal models preclude their discussion in this paper. 


\subsection{The neutral boundary layer}

\subsubsection{The Ekman layer}

Air flow over the ground will form a turbulent region in the lowest tens to hundreds of metres above the surface through the action of drag induced wind shear. The neutral boundary, which forms in the absence of temperature stratification (stable or convective) is thus a suitable starting point from which to discuss the properties of the atmospheric boundary layer.

The turbulent intensity generally decreases with height, and a measure of the depth of the boundary layer is where turbulence tends to zero, or some small fraction of the surface value. Intensity is not an indication of mixing efficiency, however, which initially increases with height before decaying to zero again at the top of the boundary layer, the exact form of mixing profile being dependent upon local and upwind conditions. If the potential temperature, $\theta(z)$, is constant with height (see Appendix I for a definition of $\theta$ ) the profile is neutrally stratified and buoyancy plays no part in modifying either the mean flow or the turbulence. Ekman (1905) was the first to describe the unique aspects of boundary layers (both oceanic and atmospheric) that form on a rotating planet: In the case of the atmosphere, in the absence of turbulence, the wind adjusts its direction so the Coriolis effect balances the horizontal pressure gradient (resulting in the so-called geostrophic wind): in this steady state the wind is perpendicular to the direction of the pressure gradient. However, near the surface, the effect of turbulence is to allow air to flow from high to low pressure (called the cross-isobar flow). Thus, the wind direction will change with height through the boundary layer. In an ideal case of flat, homogenous terrain, this wind profile within the boundary layer will be described by Ekman's equations:

$$
\begin{aligned}
& u=u_{g}\left(1-e^{-\gamma z} \cos \gamma z\right) \\
& v=u_{g} e^{-\gamma z} \sin \gamma z
\end{aligned}
$$

where $u_{g}$ is the geostrophic wind, $z$ is height. $u$ is the component of the wind parallel to the pressure contours, and hence parallel with the geostrophic wind, $v$ is the orthogonal component. $\gamma$ is a function of latitude and turbulent intensity formally described below, but at this point the interest of these equations from the polar chemistry perspective is that $\gamma$ gives an estimate of boundary layer height, at least for neutral stratification. By noting that when $z=\pi / \gamma, v$ must become zero, we can identify this height as the depth of the boundary layer. Below this level, the wind veers due to surface friction transported by turbulence, above this level, veer is zero, and we can assume turbulence and hence mixing is zero. $\gamma$ is therefore a useful scale, and is defined as

$$
\gamma=\left(\frac{f}{2 K}\right)^{1 / 2}
$$

$f=2 \Omega \sin \phi$ is the Coriolis parameter, a measure of how much the earth's rotation affects large scale flow. $\Omega$ is the angular rotation of the earth, $=2 \pi$ radians per day, or $7.27 \times 10^{-5} \mathrm{rad} \mathrm{s}^{-1}$ and $\phi$ is the latitude; hence $f$ is known exactly for any given site. $K$ is a term analogous to molecular viscosity, with units of $\mathrm{m}^{2} \mathrm{~s}^{-1}$, but accounts for turbulent exchange processes: it is referred to as an eddy diffusion coefficient. In Ekman's analysis, $K$ is assumed to be constant with height, following the molecular analogy. However, it is a major simplification and significantly inaccurate near the surface. $K$ is normally estimated from turbulence measurements by relating a measure of the flux of a quantity to its gradient. An approximation of $K$ as a function of wind speed for snow is derived below. As an indication here, for a $5 \mathrm{~ms}^{-1}$ wind $\left(K \sim 2 \mathrm{~m}^{2} \mathrm{~s}^{-1}\right)$, at Halley $\left(76^{\circ} \mathrm{S}\right.$, $\left.f=1.4 \times 10^{-4} \mathrm{~s}^{-1}\right)$, the Ekman derived boundary layer depth would be $\sim 500 \mathrm{~m}$. This is larger than generally observed at Halley during the winter, although not unknown in summer (Anderson, 2003). This indicates that vertical stratification (i.e. buoyancy) can significantly affect the boundary layer at this site. For a clear and concise derivation of these equations, see Houghton (1986), 129-130.

\subsubsection{Surface layer diffusion}

The eddy diffusivity, $K(z)$, is a concept central to understanding both the boundary layer per se, and the vertical mixing within it. It can only be measured directly by sensitive in situ sensors (see sonic anemometers below), and hence many boundary layer applications involve making parametric estimates of $K(z)$ based on more easily measured variables such as wind speed, surface radiation and, when stratification is significant, temperature profiles.

Fluxes of long lived tracers within a turbulent region are governed by the tracer gradient and the eddy diffusivity. In a real boundary layer this diffusivity is a function of height, and similarity arguments suggest that near the surface $K(z)$ is given by

$K(z)=0.4 z u_{*}$

where 0.4 is the von Karman constant, $z$ is height and $u_{*}$ is the friction velocity. This lowest region of the boundary layer is termed the surface layer and is defined as the region where vertical fluxes (e.g. of momentum or heat) are virtually constant. The surface layer is typically the lowest $10 \%-20 \%$ of the full depth of the mixing layer.

$u_{*}$ is related to the surface momentum fluxes by:

$u_{*}=\left[\left(\overline{u^{\prime} w^{\prime}}\right)^{2}+\left(\overline{v^{\prime} w^{\prime}}\right)^{2}\right]^{1 / 2}$

If the surface layer is, in fact, a "constant flux" layer, then $\mathrm{u}_{*}$ can be measured at any height within it.

Equation (6) indicates that $K(z)$ tends to zero at $\mathrm{z}=0$; at the surface there will be no diffusion. To avoid this physical unreality, the equation is assumed to hold down to a height where wind speed becomes zero, that is the roughness length, $z_{0}$. For snow, this roughness can be very small, 
e.g. $5 \times 10^{-5} \mathrm{~m}$ over an ice shelf (King and Anderson, 1994). At these scales, $K\left(z_{0}\right)$ will be comparable with molecular diffusion, which implies a smooth transition from molecular dominated diffusion within the firn, to molecular diffusion within the atmosphere at $z_{0}$, to turbulent diffusion aloft. Such simple surface layer theories allow, in principle, deduction of $z_{0}$ and the surface layer fluxes from high resolution temperature and wind profiles within the surface layer. These estimates hold well for the neutral and convective cases but are not as robust under stable stratification because turbulence does not achieve equilibrium with the mean flow in a simple manner.

\subsubsection{Surface layer diffusion with loss}

The last form to consider under purely neutral stratification is leaking diffusion, where the $1 \mathrm{D}$ version of the prognostic diffusion equation (2) includes a loss term:

$\frac{d C}{d t}=\frac{d}{d z}\left(K \frac{d C}{d z}\right)-\frac{C}{\tau}$

The first term on the right is the flux divergence formulated in terms of $K(z)$, and the second term is a loss, proportional to the local concentration, $C$, divided by a time constant, $\tau$. This equation is explored for various scenarios in Anderson and Bauguitte (2006) for a surface trace gas source, comparing the equation solutions to measurements made during the CHABLIS campaign (Jones et al., 2008). The equation generates typical profiles of concentration, $C(z)$, such as shown in Fig. 5. An intuitive feel for the shape of these profiles is useful when estimating suitable sampling levels for trace gas flux measurements, in that using a lower sampling inlet within centimetres of the surface will give a larger concentration difference compared to, say at $4 \mathrm{~m}$, but the expected curvature in $C(z)$ between the inlet tubes may become significant. The equation can be solved for diurnal variations in surface boundary conditions which generate non-stationary time series at a given height. This can be used to estimate the $\tau$ from measurements of $C(t)$ at a single level.

\subsubsection{Correlation between $h_{z}, u_{*}$ and $C$}

A number of papers have noted an apparent anti-correlation between the near surface concentration of air chemistry species and the depth of the boundary layer over South Pole $h_{z}$ (Davis et al., 2004a; Neff et al., 2008; Oncley et al., 2004). The correlation is explained in terms of surface production and containment size, in that a small $h_{z}$ implies that tracer released at the surface trapped in a small volume, and therefore accumulates to higher concentration and affects chemical reaction rates in a non-linear fashion (Davis et al., 2004a). There is also an observed correlation between $h_{z}$ and $u_{*}$ (Neff et al., 2008) in that more vigorous turbulence, reflected in $u_{*}$ at the surface, implies a greater depth of mixing before turbulence is damped out, either by stratification, the Coriolis

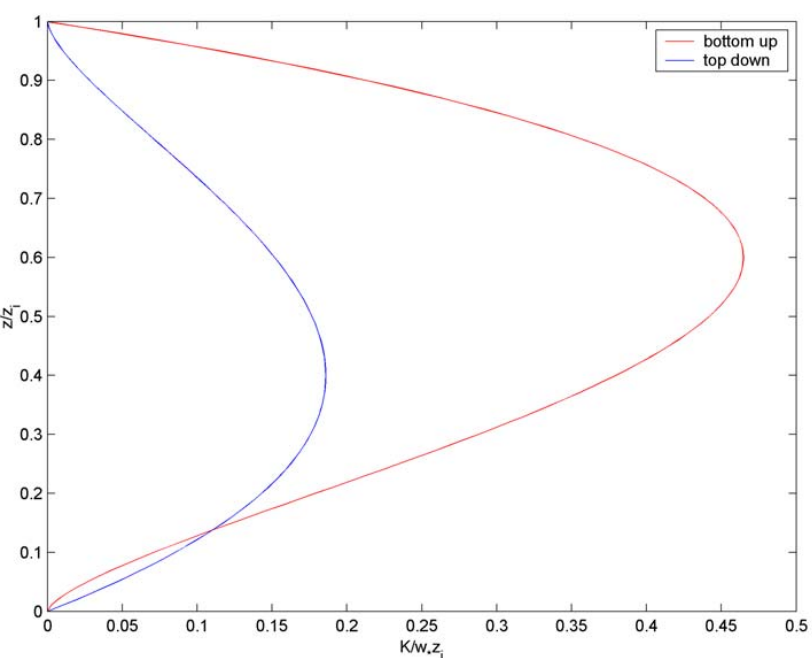

Fig. 5. Idealised and normalised diffusion curves for convection showing difference between upward and downward diffusion.

force or viscous dissipation. Given that the upward diffusivity of a tracer formed at the surface also depends on $u_{*}$, because large $u_{*}$ implies large $K(z)$, there will therefore be an anti-correlation between boundary layer depth (through momentum diffusion, i.e. $\mathrm{u}_{*}$ ) and surface produced trace gases (through enhanced vertical mixing again via $\mathrm{u}_{*}$ ). Large $u_{*}$ causes both deeper boundary layers and lower surface concentrations.

As described in Neff et al. (2008) for stable boundary layers, $h_{z}$ depends on both $u_{*}$ and the background stability. While the magnitude of $h_{z}$ can affect near surface measurements of species such as $\mathrm{NO}$ with e-folding time scales, $\tau$, of tens of hours or more, Anderson and Bauguitte (2006) argue that for a systems with short-lived species, that is where

$\frac{\tau u_{*}}{h_{z}}<5$

the depth of the boundary layer has no effect on $C$ at any level: i.e. loss though chemical interaction dominates over physical diffusion. Care is needed in the interpretation of Eq. (9) as the case depends on $\tau$ being constant: such is not the case, for instance, in Davis (Davis et al., 2004a) where the depth of the boundary layer affects the rate of exhaustion of one or more of the relevant species, and hence indirectly affects the rate constant.

Correlation between boundary layer behavior and tracer time series may occur when there is very large scale horizontal homogeneity, and the processes can be assumed to be well described by a column model. This is not the case always the case as, for example, for some of the coastal ozone depletion episodes (ODEs) at Halley (Jones et al., 2006) or ALERT (Bottenheim et al., 2002) . In some of these events, the sodar measurements or potential temperature profiles respectively indicate a change in air mass resulting from a bore 
or micro front of cold depleted air traversing the site, shown schematically in Fig. 4. Under such conditions, the depth of the boundary layer will be observed to initially increase with time, as the bore passes over the profiler, but there is no mechanism for a correlation between this depth and the tracer signature within the bore. ODE case studies highlight the need to have spatial, as well as single point temporal data if the role of the interplay between chemical processes and physical transport and mixing is to be understood.

\subsection{The Convective Boundary Layer (CBL)}

Convection occurs when the surface temperature exceeds that of the overlying air mass. It may seem that any discussion of the convective boundary layer is out of place in a discussion of snow covered polar environments, as the stable boundary layer is almost ubiquitous in these regions. Convective boundary layers have been observed during summer, however, notably at polar domes such as Dome C (King et al., 2006) and GEOSummit (Cohen et al., 2007; Cullen and Steffen, 2001) and are of special interest within the air chemistry community because their occurrence often coincides with the peak in snow photochemistry due to the insolation-driven mechanisms involved. In addition, convection is a very efficient vertical transport or mixing mechanism, whilst polar domes are sites chosen for ice core drilling.

Much of the following discussion will refer to potential temperature, $\theta(z)$, not actual temperature, $T$. The potential temperature accounts for adiabatic effects (i.e. no gain or loss of heat) as a parcel is raised or lowered in height and its temperature responds to its change in pressure. For example, a parcel displaced vertically $100 \mathrm{~m}$ will experience a change in temperature of about $0.98^{\circ} \mathrm{C}$. A well-mixed adiabatic atmosphere has $\theta(z)=$ constant. For ease of reference, Appendix I provides the conversion equations to calculate potential temperature, $\theta(z)$, from measured temperature, $T(z)$, or temperature/pressure data, $T, P:$ this latter conversion is useful when data are from radiosondes, which measure $T$ and $P$ only, and height must be derived.

The most obvious mechanism that generates a surface temperature excess is insolation, the absorption of shortwave radiation by the surface. Over snow this effect is minimized to some extent by the high albedo of the snow surface which quantifies the reflection of light from the surface. Two other mechanisms may also prevail: long-wave radiation imbalance and advection of cold air over a warmer surface.

Convection in the boundary layer is characterized by relatively thin plumes of rising air surrounded by the descending bulk of the air mass. The upper height limit of the rising plume is governed by the rate of heating at the surface and the overall temperature structure of the atmosphere: when the rising plume comes into (potential) thermal equilibrium with the surrounding air, the buoyancy force becomes zero, and, following some overshooting due to inertia, the rising air parcel comes to rest.
For the air chemistry modeling perspective, convection modifies the boundary layer in the following ways:

- Vertical diffusion (mixing) is enhanced

- The boundary layer height (mixing depth) is generally deeper than for the neutral case.

- Upward diffusion (from the surface into the mixed layer) is more rapid than downward diffusion (top of boundary layer into the mixed layer)

These aspects are treated in detail elsewhere, e.g. in Nieuwstadt (1998) and Schumann (1989), but will be discussed briefly here. The energy available to be transported by the plumes is governed by the surface heat flux, and a scaling velocity, $w_{*}$, is derived from local surface parameters:

$w_{*}=\left(\frac{g}{T_{0}}\left\langle w^{\prime} \theta^{\prime}\right\rangle_{0} h_{z}\right)^{1 / 3}$

where $g / T_{0}$, the buoyancy parameter, is the acceleration a parcel of air experiences for each degree Kelvin of excess temperature, $g$ is the acceleration due to gravity, $\left(9.81 \mathrm{~ms}^{-2}\right)$ and $T_{0}$ is the surface temperature in Kelvin, $\left.\mathrm{K} .<w^{\prime} \theta^{\prime}\right\rangle$ is the kinematic sensible heat flux as measured by eddy covariance, with units of $\mathrm{K} \mathrm{m} \mathrm{s}^{-1} . h_{z}$ is the height of the mixing layer in metres.

In the absence of covariance measurements, $\left\langle w^{\prime} \theta^{\prime}>\right.$ must be approximated from the surface energy balance:

$\left\langle w^{\prime} \theta^{\prime}\right\rangle \cdot \rho C_{p}+R n+G+H_{\lambda}=0$

where $\rho$ is the air density and $C_{p}$ is the specific heat at constant pressure $=1005 \mathrm{~J} \mathrm{~kg}^{-1} \mathrm{~K}^{-1}$. Rn is the net radiation flux, and $G$ the heat flux into the snow. If the surface is not melting, $\left(<0^{\circ} \mathrm{C}\right) \mathrm{G}$ is usually small compared to $R n$ and in $e x$ tremis can be neglected. Similarly, at cold temperatures, the vapour pressure for water is small, and the latent heat flux, $H_{\lambda}$, can be neglected. On balance, it is best to measure $<w^{\prime} \theta$ ' $>$ if possible.

There are two different diffusivities associated with the CBL, depending on the direction of diffusion (Nieuwstadt, 1998; Schumann, 1989). Bottom-up diffusion is more efficient than top-down due to the thinner plumes of ascending air rising more rapidly than the descending air. Figure 6 shows the two diffusion coefficients plotted on dimensionless axes. Height ( $y$ axis) and diffusion ( $x$ axis) are normalised using $w_{*}$ and $h_{z}$ : once these two scales are known, the form of the plots provide an estimate for the diffusion of tracer within the CBL.

The form of the two dispersion coefficients, $K_{b}$ ("bottom up", i.e. suitable for tracer released at the surface) and $K_{t}$ ("top down", i.e. suitable for tracer entrainment at $h_{z}$ ) are:

$$
\begin{aligned}
& K_{b}=2.5\left(1-\frac{z}{h_{z}}\right)\left(\frac{z}{h_{z}}\right)^{3 / 2} \\
& K_{t}=\left(\frac{z}{h_{z}}\right)\left(1-\frac{z}{h_{z}}\right)^{3 / 2}
\end{aligned}
$$




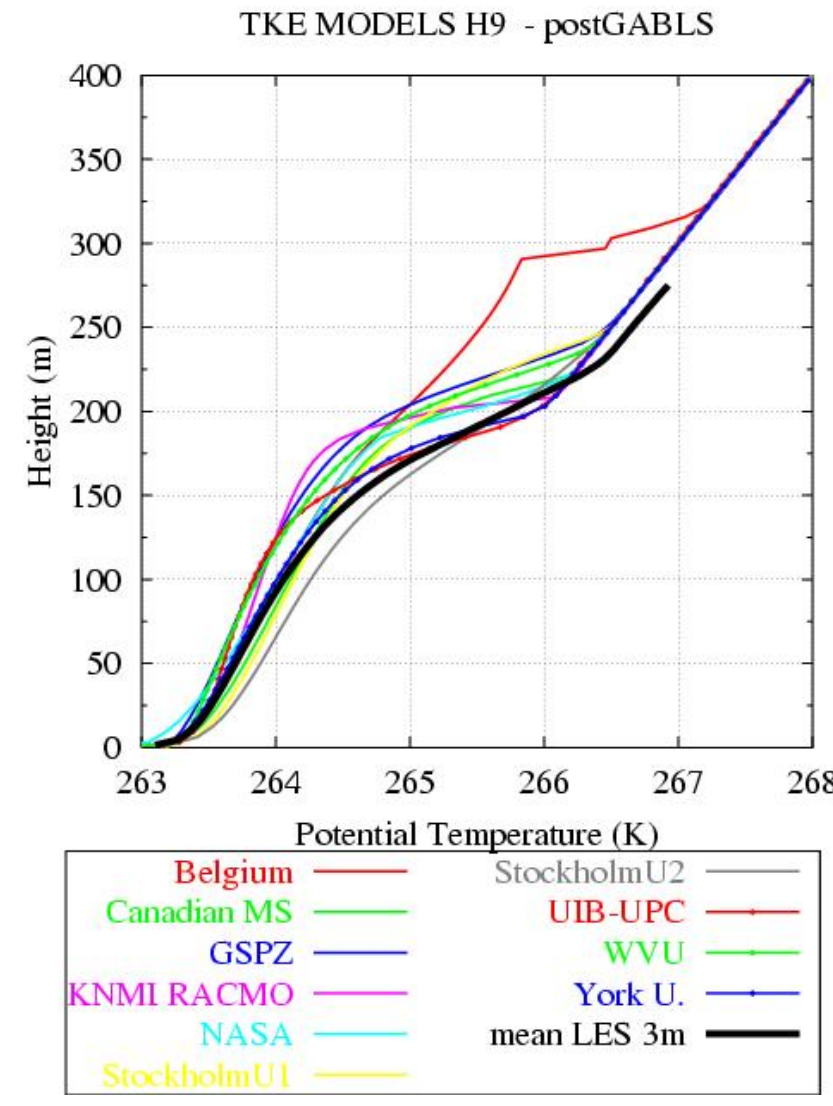

Fig. 6. Comparison of temperature profiles from state-of-the-art 1D SBL models. Initiated with weak stable gradient, constrained by an explicit gradual surface cooling, fixed geostrophic wind speed and upper level temperature. For this simplest of cases, where only the internal shape of the profile may differ, the various models exhibit a wide range of cooling rates and resultant profile gradients.

\subsection{The moderately Stable Boundary Layer (SBL) over flat} terrain

The stable boundary layer is almost ubiquitous in polar regions, due to the combined effects of long-wavelength infrared radiation from the surface and the reflection of shorter visible wavelengths from the snow at the low sun angles characteristic of the polar regions. The low absolute humidity of the atmosphere and frequent cloud free conditions also contribute to the net loss of radiation from the surface and the cooling of the atmosphere from below. The prevalence of the SBL in polar regions provides challenges for both the meteorological and the air chemistry communities insofar as the physics of the SBL is still poorly understood (Mahrt, 1999). Simple parametric schemes for the vertical diffusion profile are not valid, and various non-local schemes are required to include flow history and other non-local mechanisms such as buoyancy-related wave motions. For the SBL, micrometeorological measurements are essential. There are a few situations where things are not so bleak: the weak SBL over

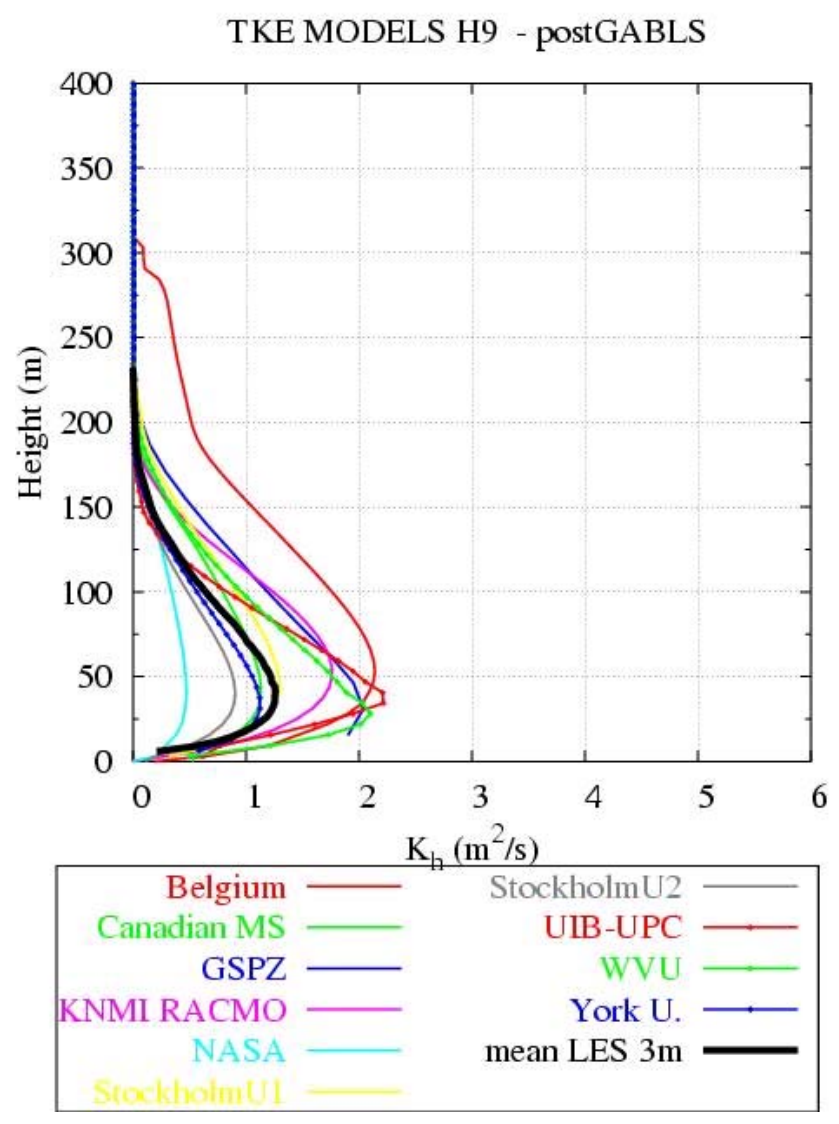

Fig. 7. As for Fig. 6 showing diffusivity profiles. A significant variation in profile shape and maximum diffusivity is apparent, which is of concern given that the model runs were for a fairly moderate stratification, and with fixed upper and lower wind speed and temperature. In real situations, the lower constraints are the controlled by the surface energy balance, and surface temperatures may decrease rapidly.

(very) flat terrain, and in those cases where wind and turbulence can be maintained at some minimum level due to katabatic forces can be amendable to modeling such as the recent results of Wang et al. (2008). However, BL measurements are required to estimate when conditions are suitable for applying the limited understanding we do have of the SBL.

The CBL has an inherent negative feedback in the diffusion: if the bulk or mean $K(z)$ becomes too great, heat is removed from the ground too rapidly so that the temperature excess that generated the convection is removed. The reverse is true of the SBL. Stability is initially generated by a surface cooler than the overlying air. $K(z)$ enables the air to transfer heat to the surface. Stability acts to reduce turbulence, hence mixing and hence $K(z)$. If $K(z)$ is reduced, less heat reaches the ground, it cools more rapidly, and increases the stability even more. The SBL has an inherent positive feedback, making it, at best, highly sensitive to forcing such as cloud cover or wind speed. In extreme cases, the SBL can 

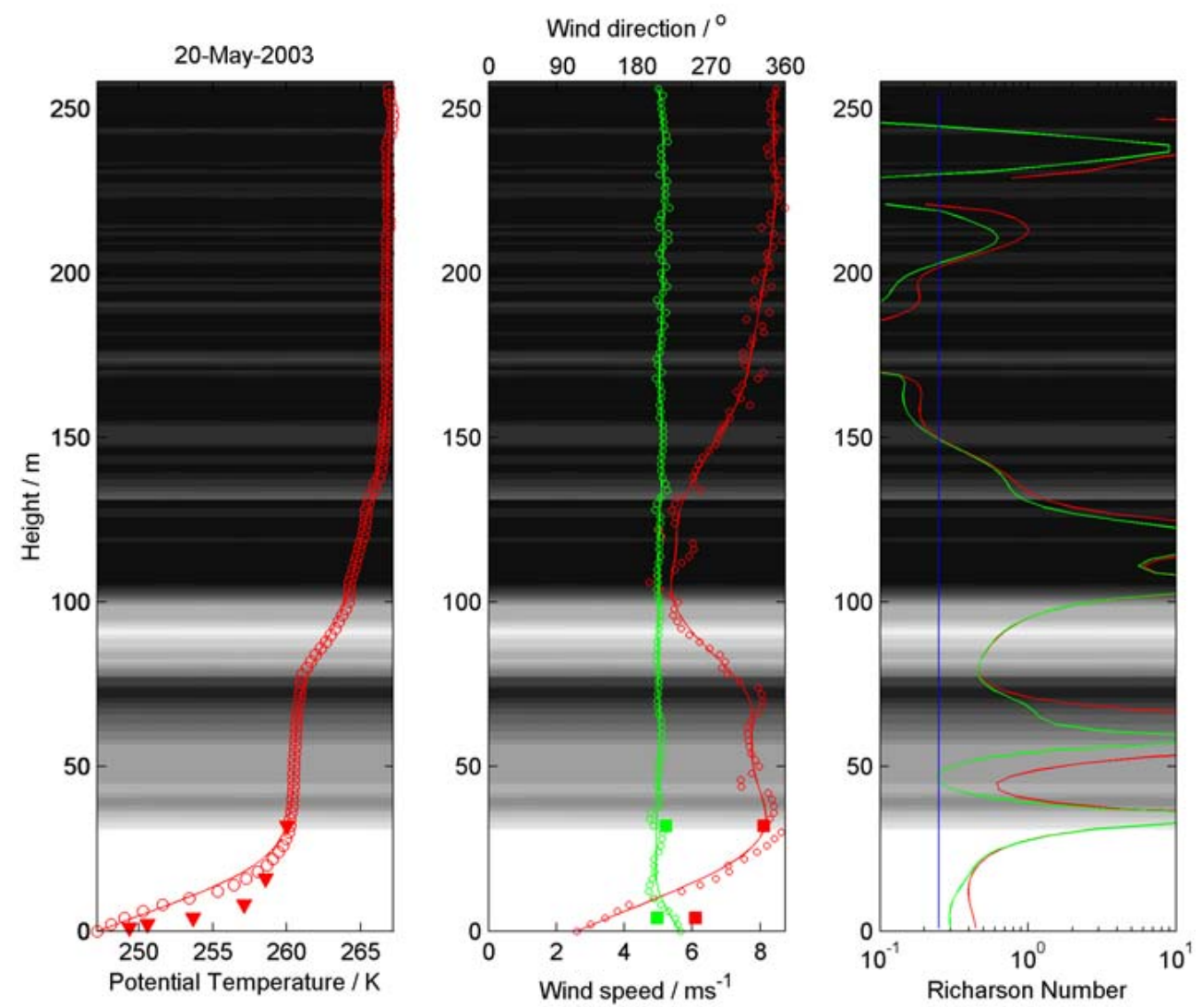

Fig. 8. Profiles of temperature, wind speed and Richardson number for a stable ABL over flat terrain, collected by tethersonde and profile mast at Halley on 19th May 2003. Circles are sonde data, solid lines are the same data smoothed by a 13 point Hamming filter. Triangles are mast mounted aspirated thermometers, squares sonic anemometers. The plots show two levels of mixing depth as might be interpreted from these data. Firstly, the "top of inversion" and low level jet maximum are somewhere between $20 \mathrm{~m}$ and $30 \mathrm{~m}$, , whilst there is still mixing apparent up to $80 \mathrm{~m}$ interpreted from the residual temperature gradient and low Ri. The background shading is $C_{T}^{2}$ (sodar echo strength) implying mixing occurs up to $75 \mathrm{~m}$.

become completely devoid of mixing in which case radiative fluxes dominate heat transfer within the boundary layer and at the surface. This section reviews the techniques suitable for a SBL in which turbulence is still (relatively) active at all levels. The more extreme cases are discussed below.

A common measure of dynamical stability is given by the Richardson Number, $R i$, of which there are a variety of forms, but all aim to be measure of the balance between the generation and the destruction of turbulence in a stratified flow. In the simple SBL (i.e. ignoring complexities such as waves, orography), wind shear generates turbulent energy. Conversely, the effects of buoyancy remove energy from the turbulence. $R i$ represents the balance between these competing mechanisms:

$$
R i=\frac{\frac{g}{T} d \theta / d z}{\left[(d u / d z)^{2}+(d v / d z)^{2}\right]}
$$

The temperature gradient term in the numerator reflects the inverse of a buoyancy time scale, the wind gradient term in the denominator, reflecting the shear in both wind speed and direction, represents the inverse of a turbulence time scale. Under neutral conditions, with no buoyancy, $R i=0$. As stability increases, $R i$ increases. Theoretical and wind tunnel studies have shown that for large $R i$, the flow is likely to fully laminar: as $R i$ is reduced to 0.25 , dynamical instability can develop as the wind shear overcomes the effect of stability and thus produces turbulence. However, complications ensue when the $R i$ of a flow varies above and below 0.25 , often leaving a residue of isolated turbulence even at larger $R i$.

Unlike the neutral and convective boundary layer, there are as yet no simple prognostic equations for the diffusivity aloft, nor the depth of the mixing layer. Some inherent features of the stable boundary layer can be captured by considering a slightly stable case, where the temperature gradient is initiallyconstant. Figure 7 (temperature) and Fig. 8 (diffusivity) show how such a model boundary layer evolves if the surface- and upper-level temperatures are fixed. Mixing near the surface reduces the temperature gradient, whilst reduced mixing at mid-levels allows the development of an 


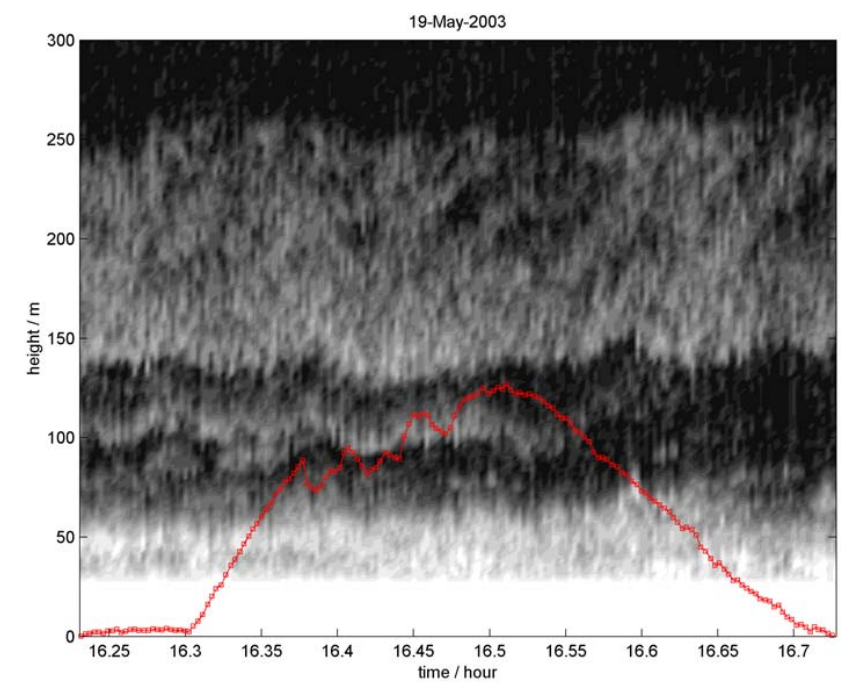

Fig. 9. Sodar echogram for the tethersonde flight in Fig. 8; lighter shading implies stronger echo return from turbulence acting on the temperature gradient. Note that the descent data are presented. The echogramme gives a qualitative indication of mixing depth, $h_{z}$, but there is still debate as to exact matching of derived $h_{z}$ from sodar, temperature or extrapolated turbulence data. The flight position of the sonde is indicated in red.

"inversion" at the top of the boundary layer. The strong gradients at this inversion enhance the stability, and suppress mixing further. The result is a boundary layer potential temperature profile, $\theta(z)$, with positive curvature, that is $\mathrm{d}^{2} \theta / \mathrm{d} z^{2}>0$; the $\theta(z)$ is concave to the right. This is for an idealized case where there is no net surface cooling; even so, there are significant differences between models for this most simplified of stable cases. For a description of the comparison, see Cuxart et al. (2006), Holtslag (2006), Kerstein and Wunsch (2006) and Steeneveld et al. (2006). Compare these figures with observed profiles, where surface cooling does occur. Figures 9 and 10 are tethersonde profiles and sodar echogramme recorded at Halley during the winter of 2003. The rapidity of the cooling results in a profile where $\mathrm{d}^{2} \theta / \mathrm{d} z^{2}$ is negative, that is, the profile is concave to the left. Such $\theta(z)$ profiles are ubiquitous at Halley where the absence of slope precludes the onset of drainage flow. Drainage, or katabatic flow, acts to limit the magnitude of the temperature gradient by maintaining the strength of the near surface turbulence.

Real SBLs are often complex, in that the variation of $K(z)$ aloft affects the temperature gradient itself. Near the surface, $R i$ tends to small values (except under near calm wind conditions), and the diffusion is relatively well behaved. Aloft, however, the wind shear reduces, whilst the temperature gradients remain relatively constant; hence $R i$ generally increases with height until turbulent activity is affected. Feedback between stability and diffusion is then highly non-linear, and the predictive ability of boundary layer theory becomes poor. For a more thorough overview of

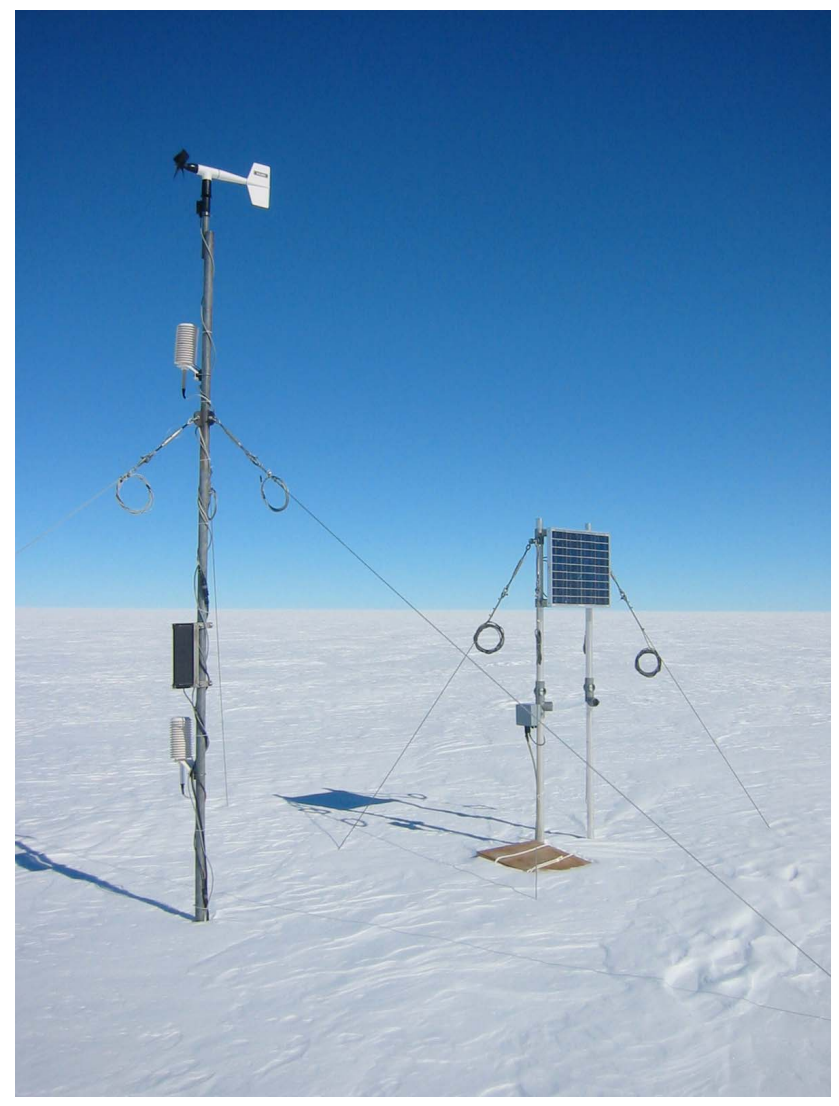

Fig. 10. Typical winter-over polar AWS deployed in Coats Land. Note the propeller-vane anemometer which is less susceptible to icing errors, and the twin temperature sensors (inside radiation shields) to record temperature gradient. The mast is kept free of logging boxes and solar panels to reduce wind flow distortion.

the difficulties in parameterising the stable boundary layer, see Mahrt (1999), Mahrt and Vickers (2006), Vickers and Mahrt (2004), Zilitinkevich and Baklanov (2002) and Zilitinkevich et al. (2002).

What then can be done to calculate the diffusion profile, $K(z)$ ? Two options are available, neither ideal. First is to use a 1-D SBL model which can produce $K(z)$ as a diagnostic when turbulence parameterizations are explicitly included in the numerical calculation. Such models are constrained by measurable boundary conditions, the most important being wind speed and snow surface temperature, $T_{s}$. If $T_{s}$ is left free, such models for flat terrain tend to dramatically over or under estimate the temperature gradients, due to the internal sensitivity of these models. At present, 1D SBL models appear to be very poor at reproducing observed temperature profiles because they do not account for the upstream history of the boundary layer flow. There is a lack of in situ measurements of $K(z)$, but the failure of the temperature validation implies there will be a similar discrepancy between model and real diffusivity profile. 
The second approach is to rely on measurement, and is it the SBL which most benefits from the sodar and sonic anemometer data. Sodar images will indicate when the SBL is well behaved and therefore suitable for thorough analysis, and thence also indicate the depth of the mixing layer. The sonic anemometry assists in constraining and testing the validity of model diagnostics. For flat terrain, there are frequently events where the sodar echo signature exhibits complex structure aloft, this being prevalent under moderate to calm wind conditions. With slightly higher winds, the sodar data implies a well ordered SBL, with a clear measurable upper limit. It will be these occasions when air chemistry modeling, based on some prescribed $K(z)$ profile, will be most valid.

\subsection{The stable SBL over sloping terrain}

Much of the interior of Antarctica is characterized by small terrain slopes $(\sim 0.001$ to 0.002$)$, strong wintertime temperature inversions and relatively weak summertime inversions. Much of our understanding of the micrometeorology of this region and its linkages to the large scale circulation has come from studies at the South Pole (Neff, 1999; Neff et al., 2008; Neff, 1980). In very general terms, radiative cooling for the surface, which prevails even in summer except for overcast periods (Carroll, 1984), creates a surface temperature inversion overlying the sloping ice surface. This creates a downslope pressure gradient which under weak synoptic forcing results in a very constant Ekman layer flow. In addition, the large-scale pressure gradient is often also downslope leading to persistent downslope winds even in summer. Because there is no diurnal cycle, this is a unique location for the study of stable boundary layers modulated primarily by only synoptic scale weather systems. As noted by Neff (1999), the winds aloft are typically bimodal leading to an alternation between an upslope and downslope oriented large scale pressure gradient. When this pressure gradient is oriented upslope, it opposes that created by the effect of the inversion overlying the sloped surface and winds become very light but typically non-zero. Because such conditions typically occur with clear skies, very strong inversions also form, creating a contradiction with the traditional conceptual picture of strong inversions resulting in downslope flows. When the winds aloft reverse, the pressure gradient becomes downslope with stronger surface winds, increased mixing, weaker inversions and deeper boundary layers. These conditions usually occur with increases in cloudiness and thus radiative cooling of the surface is of less influence.

Recent interest in this meteorological environment has been stimulated by observations of very high nitric oxide concentrations at the South Pole in 1998 and 2000 (Davis et al., 2001) and thought to be due to the non-linear growth in NO associated primarily with very shallow boundary layers (Davis et al., 2004a). A follow-on study in 2003 added a number of measurements to document the boundary layer properties and vertical profile characteristics for $\mathrm{NO}$ and $\mathrm{O}_{3}$ (Helmig et al., 2008a, 2008b; Neff et al., 2008). Together with sonic anemometer turbulence measurements and data from a 22-m tower, this experiment provided a unique opportunity for relating surface chemistry to the slowly changing meteorology of a stable boundary layer. Key findings from this study include

- Both boundary depth and NO depend on $\mathrm{u}_{*}$ : i.e. a small friction velocity results in limited mixing and high NO values.

- Simple boundary layer depth scaling results, using $\mathrm{u}_{*}$ and stability, agree well with sodar-observed mixing layer depths.

- Estimated vertical diffusion times to depths of $30 \mathrm{~m}$ are on the order of nine hours under light wind conditions, sufficient to allow non-linear NO chemistry to be activated which occurs with NO concentrations in excess of 200 pptv, when NO increases result in $\mathrm{OH}$ reductions: (Davis et al., 2004a).

- Observed sodar mixing layer depths agreed well with those calculated from a 1-D model (Wang et al., 2008).

- The use of a sodar to provide consistent mixing-layer depth estimates allowed identification of anomalous periods that could only be explained by increased fluxes of NO from the snow.

\section{Measurement techniques, instruments and field stud- ies}

A boundary layer air chemistry campaign will generally benefit from some level of micro-meteorological data, in order to understand local mixing and transport. Instrumentation and deployment costs will limit the availability of these data. This section describes typical micro-meteorological field instrumentation which would benefit major air chemistry campaigns, roughly in order of increasing cost and usefulness.

\subsection{Automatic Weather Stations (AWS)}

A typical AWS will measure wind speed and direction, temperature, humidity and pressure near the surface. Additional instruments are often deployed, such as an additional temperature sensor, radiometers and snow depth sensors. Commercial units tend to come equipped with solar panels for power and telemetry, to send data back to the user. In polar environments, these units must be modified, or custom designs used, to cope with the harsher environment, lower temperatures, lack of communication infrastructure and long polar nights. A useful guide to suitable AWS for polar work is provided by (Oerlemans and Tijm-Reijmer, 2004). This manual discusses the present optimum instrument designs to deploy over snow, 


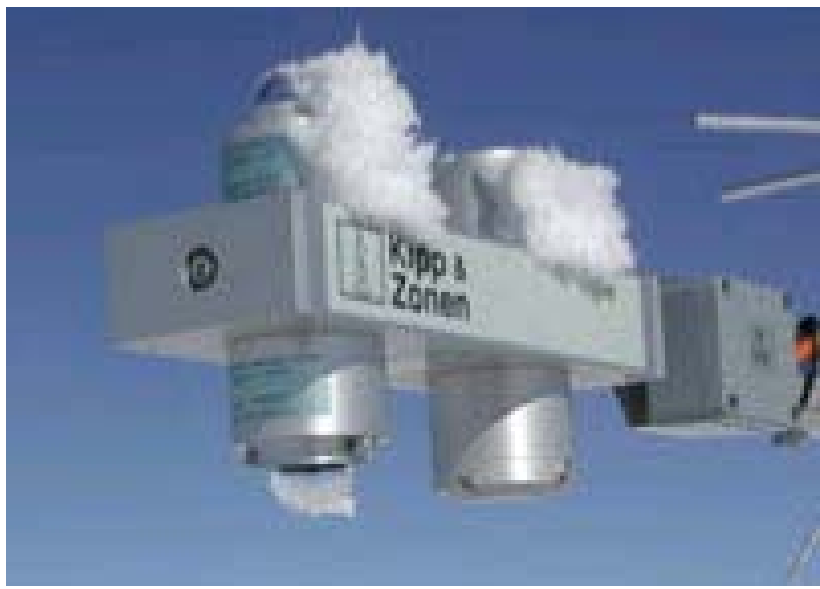

Fig. 11. Four-component radiation sensor on AWS9, at Kohnen Station, Antarctica (CNR1, from Kipp and Zonen). Icing can be a problem on these sensors, but careful cross-analysis of the data can indicate when icing is present. Photo courtesy of M. R. van den Broeke.

such as preferring propeller-vane wind instruments over cup anemometers.

The AWS will only provide limited information on the structure of the boundary layer, the data being used as if standard meteorological data were available (Jacobi et al., 2000; Jones et al., 2001). $u_{*}$ can be estimated from wind speed, assuming neutral stratification and a known or estimated roughness length.

A temperature measurement at a second level ( $>2 \mathrm{~m}$ vertical from the first sensor) identifies when strong, stable stratification exists. This stratification will modify the vertical mixing from the surface, but this can be estimated along with the down-welling sensible heat flux (van den Broeke et al., 2005). Unfortunately, convection cannot be distinguished from neutral stratification by a pair of temperature sensors, due to insolation errors on the sensors, and the much smaller temperature gradients associated with convection. In addition, AWS deployed for longer periods of time may be subject to drifting snow and accumulation, thus changing the effective height of the measurements. Figure 11 shows a typical polar AWS deployed in Coats Land.

\subsection{Radiometers}

Micro-meteorological radiometers are broadband instruments used to help characterize the radiative components of the surface energy budget, critical to the evolution of mixing in the boundary layer. Radiometers may be added to the standard AWS equipment, but due to power constraints such sensors are generally un-aspirated, and can therefore be adversely affected by rime-icing. Better data can be obtained using aspiration over the domes, which maintains the optics. Aspiration, however, requires significant power, only avail-

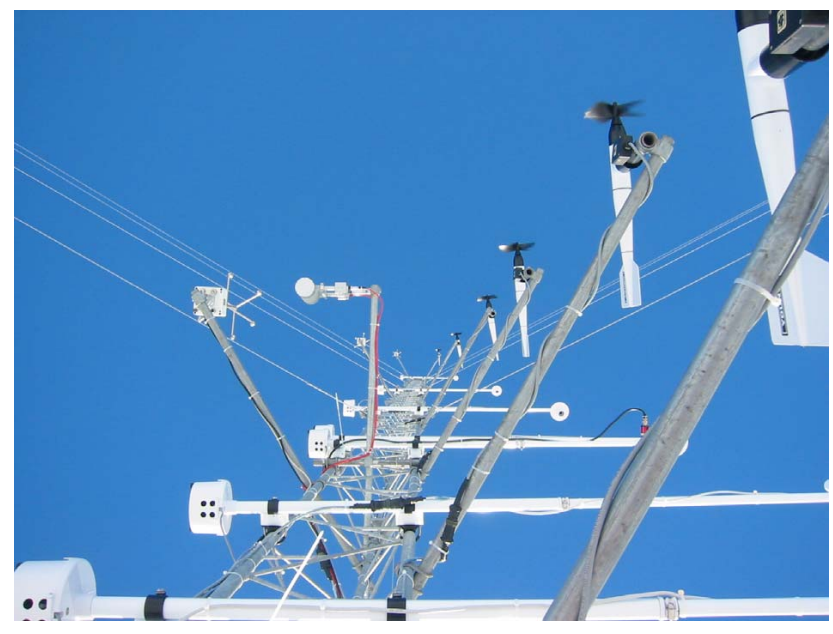

Fig. 12. View up a typical boundary layer profile mast, showing (on RHS) mean wind and temperature sensors at $1,24,816$ and $32 \mathrm{~m}$ levels. On the left are turbulence sensors, with three sonic anemometers at 4, 16 and $32 \mathrm{~m}$, and an infra-red hygrometer (IRH) at $4 \mathrm{~m}$. The IRH allows moisture flux to be estimated using the covariance of humidity with the pseudo-co-located turbulence data. Image from Halley, 2003.

able in summer (photovoltaic) or by wind turbine or station generator. A good set of upward and downward longwave and short wave radiometer readings can give information on net radiative cooling or warming, cloud cover (by comparing long-wave readings), insolation and albedo. Figure 12 shows the four component CNR1 radiation unit, typically used on AWS, where no heating or aspiration power is available to reduce icing.

\subsection{The Profile mast}

Over snow/ice, masts $>30 \mathrm{~m}$ are difficult to maintain, and masts much below $10 \mathrm{~m}$ fall into the AWS category. A "profile mast" refers to $20-30 \mathrm{~m}$ height, and rigged with instruments arranged with logarithmic vertical spacing. Standard observations are winds and temperature, aimed at measuring the gradients, that is the near-surface wind shear and lapse rate. Measuring gradients requires a higher level of accuracy from the equipment than from an AWS, and polar profile masts invariably have aspirated temperature / humidity sensors, and require frequent observations to check for icing. Figure 13 shows the $32 \mathrm{~m}$ Instrumented Clean Air Sector (ICAS) mast at Halley, Antarctica, located $50 \mathrm{~m}$ from the Clean Air Sector Laboratory (CASLab).

\subsection{Sonic anemometers/thermometers}

The de facto boundary layer micro-meteorological instrument is the sonic turbulence sensor or sonic anemometer/thermometer. This instrument measures wind and temperature by measuring the time of flight of ultra-sound pulses 


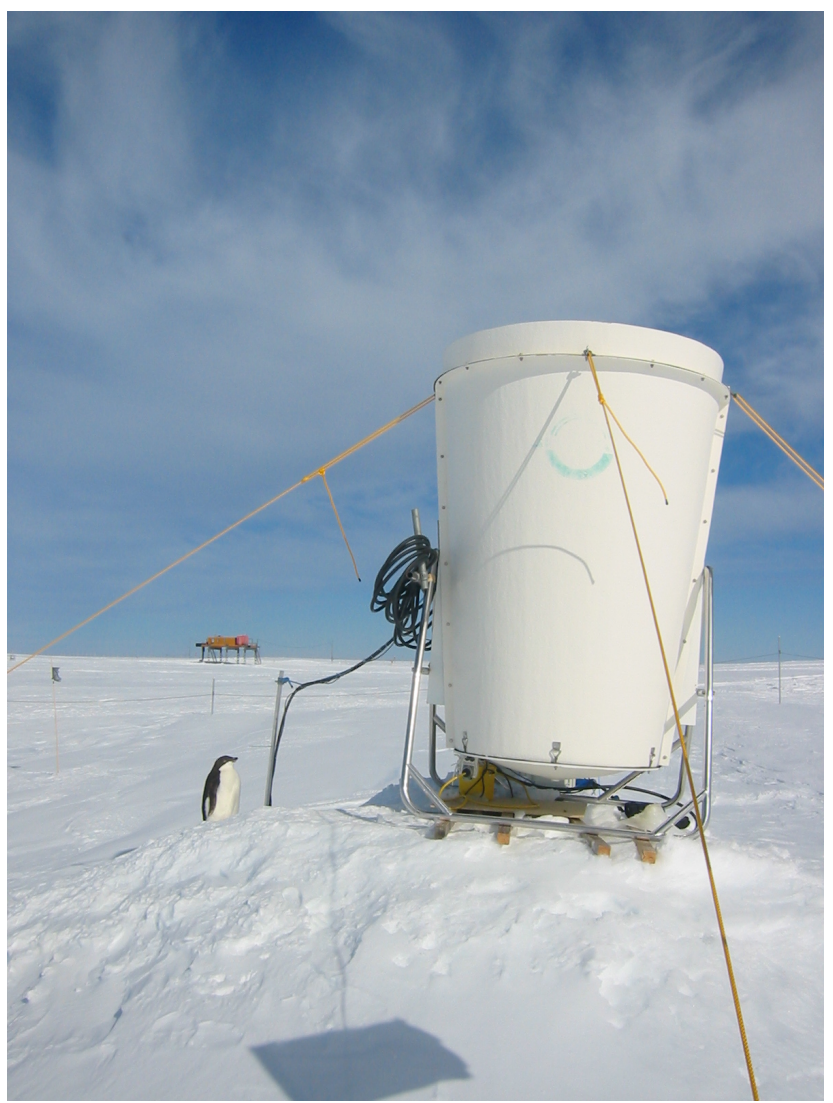

Fig. 13. Simple acoustic sounder (sodar) at Halley. The bulk of the antenna is a hollow cone that acts as acoustic shielding to reduce side echoes and background noise: the base is a focusing dish to produce a vertical acoustic beam for transmission and reception. Off-station acoustic sounders are now available, which use an array of small transceivers to produce the same effect. Note that the antenna is off-vertical due to insolation melting the snow berm.

over a path of $10-20 \mathrm{~cm}$, and can explicitly resolve the dominating eddies in all but the most stable boundary layer flow. These are usually mounted at heights in excess of $2 \mathrm{~m}$ above the surface. Closer to the surface or under very stable conditions, caution must be exercised because the sonic anemometer may not capture eddy motions close to the path length of the instrument. Typically, examination of the spectra reveals any shortcomings in the data.

By calculating the covariance of the vertical wind fluctuations, $w^{\prime}$, with other wind vectors ( $u^{\prime}$ and $\left.v^{\prime}\right)$, or with fluctuations of scalars such as temperature, $\mathrm{H}_{2} \mathrm{O}$ or $\mathrm{CO}_{2}$, the flux of momentum, heat, moisture and $\mathrm{CO}_{2}$ respectively can be measured directly. There are some assumptions and instrument corrections involved in the technique, but eddy covariance provides the most direct measurement of vertical fluxes. The difficulty in using eddy covariance for scalars other than temperature is to locate a sufficiently fast response sensor within, or close by, the sonic anemometer sample volume ("open path" eddy correlation) or ensuring the tracer sampling tube in "closed path" eddy correlation does not adversely affect the response time of the whole system. For open path sensors, there is the additional difficulty of ensuring the sensor is small enough to generate minimal flow distortion.

Sample tubes, even accounting for delay, are prone to averaging errors due to the non-uniform flow rate cross-section within the tube (McKeon and Morrison, 2007). If this averaging time scale is greater than that of the time scale of the eddy motions, the fluxes will be under estimated. Closedpath eddy correlation under stable conditions is more challenging, therefore: the constant flux region where the sonic is usually mounted is near the surface $(\sim 4 \mathrm{~m})$, and the corresponding eddy frequency well below $1 \mathrm{~Hz}$ (Baas et al., 2006; Stull, 1988). The situation is even worse for stable stratification.

An alternative to direct eddy correlation is relaxed eddy correlation (REA), also known as conditional sampling, where the sonic anemometer vertical wind channel triggers a valve system, which then sends down welling air to one sensor, and upwelling to another (Fotiadi et al., 2005). REA flux measurements are a step away from direct eddy covariance and can only be used with tracers that do not react within the accumulation volume or tubing. They can be highly sensitive and the method avoids the need for fast response tracer instruments and the issue of tube averaging. Sufficiently fast sensors are now available or under development for $\mathrm{H}_{2} \mathrm{O}, \mathrm{CO}_{2}$ in open path form, and for ozone and $\mathrm{NO}_{\mathrm{x}}$ in closed path using chemiluminescent sensors (Horii et al., 2006; Ulanovsky et al., 2001).

Sonic anemometers require a significant level of understanding to ensure that the processed data are reliable. They are sensitive to a number of deployment effects, such as tilting or mast shadow, and require corrections to compensate for flow distortion around the sensor as well as other effects. Lee et al. (2004) is an essential guide to the present state of the art of sonic anemometer data analysis.

Sonic anemometers require significant power compared to AWS and radiometer, and again tend to be used either in summer only (with photovoltaics) or use station power. The instruments can be operated autonomously, but are sensitive to icing, hence require heated transducers. One sonic at two metres elevation can make a fair estimate of vertical transport by measuring $u *$ directly, and under katabatic conditions, estimate boundary layer depth (Neff et al., 2008) as well as giving wind speed, direction and temperature. The data can be logged at their raw output rate (typically $40 \mathrm{~Hz}$ ) and the fluxes calculated afterwards. Some units calculate these fluxes and their mean value in real time. Putting sonics at various heights on a profile mast enhances the value of the data, partly as a check on data quality, but also to ensure that measurements from the mast are representative of surface values, that is, there is a negligible gradient of fluxes between the lowest instrument and ground. Figure 13 shows the ICAS mast with three sonic anemometers deployed. These units have sensor heating to reduce icing difficulties. 


\subsection{Acoustic radar or sodar}

The structure of the near surface atmosphere can be qualitatively visualized using acoustic radars (Neff and Coulter, 1985). Sound will scatter from temperature inhomogeneities in the atmosphere, generated by wind shear acting on the temperature gradient under stable conditions or by convective elements rising from a warmer surface and mixing into the ambient fluid. Interpretation of the echo images is nontrivial, but the instrument has the ability to detect the upper level of the near-surface mixing directly. During convection the top of the boundary layer is often clearly visible on acoustic radar (sodar) due to the strong temperature gradients often associated with the region (see Fig. 1 for typical convective profiles), hence the sodar data are highly desirable in order to get $h_{z}$.

There are two main types of sodar applications: backscatter profiling and wind profiling. The latter is invariably provided by the commercial sector, which markets the units as a replacement for expensive profile masts. The boundary layer and air chemistry research community are becoming more familiar with the original backscatter-only system, which provide profiles of the temperature structure function, often referred to as $C_{T}^{2}(z)$. These sodars are relatively simple but invariably a non-commercial, in-house unit. These units are tuned to provide high resolution in the vertical, with one metre being typical, and under suitable conditions resolve the $C_{T}^{2}$ mixing depth to high accuracy, as well as provide indications of internal boundary layer structure (Anderson, 2003; Culf, 1989). Standard sodars provide echo data from $20 \mathrm{~m}$ above the surface to around $1000 \mathrm{~m}$, whilst mini-sodars work from $1 \mathrm{~m}$ to $200 \mathrm{~m}$. They can operate autonomously given suitable care with the design and a robust power system (Anderson et al., 2005). Figure 14 shows the sodar used to assist interpretation of the CHABLIS data (Jones et al., 2006).

\subsection{Balloon sondes (RAWINsonde)}

The free flight balloon with meteorological instrument package will provide limited immediate data for use in air chemistry analysis, but, if the data are linked to the global analysis data centres (i.e. weather forecasting) the data will enhance the product in the locality of the field study. Meteorological balloon sonde systems are invariably commercial. Chemical balloon profiling is expensive, and geared for stratospheric studies, notwithstanding the analysis by Tarasick and Bottenheim (2002).

\subsection{Tethersondes}

The tethered sonde system, whereby an instrument package is taken aloft and subsequently recovered, is well suited to boundary layer air chemistry studies. With recovery virtually guaranteed, custom designed or bespoke instrument packages can be used. Simple filter sampling at constant height can be achieved using a relatively rapid ascent of the sonde followed by a period at constant altitude (Rankin and Wolff, 2002). True profiling has become feasible in recent years by combining relatively standard meteorological tethersondes with novel, light weight, air chemistry instruments. The latter may log on-board, or, as per typical free flying ozone "sondes", piggy-back onto the telemetry of the meteorological tethersonde. Profiling the chemistry and boundary layer meteorology with the same package is highly desirable, as there is frequently apparent co-spacial structure in both the tracer signature and the potential temperature profile.

Recent advances associated with the ANTCI program have revealed the value of balloon profiling for $\mathrm{NO}$ and $\mathrm{O}_{3}$ (Helmig et al., 2008a, 2008b). In the case of NO profiling, sampling is through a long tube and the delay in the sampling tube requires correction.

The lifting platform can be either blimp or kite, depending on wind conditions and logistics and to some extent, the expected temperature. Kites are less susceptible to microdamage from cold temperature effects on the material, and are more portable for field work. Blimps work in lower wind speeds, and can be flown with simpler winch systems, due to the lower line tensions required for lifting the same mass of sonde. They do require a significant helium source, reducing their suitability for remote operations.

\subsection{Remote sensing}

The atmospheric boundary layer is poorly understood, in part due to the limited use to which satellite data can be put to probe the atmosphere close to the ground; ABL studies require in situ measurements and suffer from the resulting lack of spatial information. One major exception is the retrieval of surface temperatures from infra-red imagery, assuming no cloud cover. The visualisation of extreme mixing within the ABL due to, say, strong katabatic flow is also possible, as shown in Bromwich et al. (1992) but vertical profiles, fluxes or upper boundary layer mixing cannot, as yet, be measured by these techniques.

\section{Summary}

The physics of the boundary layer is of growing interest to the air chemistry and snow chemistry community. Despite the development of 1-D ABL chemistry models (Saiz-Lopez et al., 2008), which are extensions of existing physical ABL models, a knowledge of the typical behaviour and known failings of such physical ABL models is beneficial to the community. Invariably, such models benefit from additional constraints derived from in situ measurements of the micrometeorology. This paper has provided the main conceptual principals underlying ABL theory and associated models, and provides examples of useful micro-meteorological equipment to augment polar atmospheric air chemistry campaigns. 
Edited by: P. B. Shepson

\section{Appendix A}

\section{Useful equations}

For the derivation and a clear discussion of how to use these equations refer to (Stull, 2000)) where these forms are presented in difference notation, not as true integrals, which is most appropriate for working with digitised (finite step) data.

Ideal Gas Law: relates pressure, temperature and volume of a gas.

$P=\rho \Re_{d} T$

Where $P$ is the pressure in $\mathrm{Pa}, \rho$ is density in $\mathrm{kg} \mathrm{m}^{-3}, T$ the absolute temperature in $\mathrm{K}$, and $R_{d}$ is the gas constant, = $287.053 \mathrm{~J} \mathrm{~K}^{-1} \mathrm{~kg}^{-1}$.

Hydrostatic Equation: gives the change in pressure with height if the density of the air is known.

$$
\frac{\Delta P}{\Delta z}=-\rho g
$$

$\Delta P$ is change in pressure in $\mathrm{Pa}, \Delta z$ is change is height. $\rho$ is density in $\mathrm{kg} \mathrm{m}^{-3}, g$ is acceleration due to gravity $=9.81$ $\mathrm{ms}^{-2}$

The Hypsometric Equation. A combination of the ideal gas law and the hydrostatic equation, gives the change in height associated with a change in pressure for a given (mean) temperature

$z_{2}-z_{1}=a T \ln \left(\frac{P_{1}}{P_{2}}\right)$

where $z_{1}$ and $z_{2}$ are heights, $P_{1}$ and $P_{2}$ the respective pressures, and $T$ the mean absolute temperature between these heights. $a=\mathrm{R}_{d} / \mathrm{g}=29.3 \mathrm{~m} \mathrm{~K}^{-1}$.

Potential Temperature Conversion from Pressure

If the temperature is know as a function of pressure, for instance in a radiosonde profile,

$\theta=T\left(\frac{P_{0}}{P}\right)^{\Re / C_{p}}$

where $P_{0}$ is the pressure at the surface (or some reference pressure e.g. $1000 \mathrm{hPa}$ ), and $C_{p}$ is the specific heat at constant pressure $=1005 \mathrm{~J} \mathrm{~kg}^{-1} \mathrm{~K}^{-1}$ (assumes dry air which is reasonable for most polar temperatures).

Potential Temperature Conversion from Height To calculate the true potential temperature If only a temperature profile, $T(\mathrm{z})$ is known, the calculation of potential temperature first requires calculation of the respective pressure "profile", $P(z)$. Firstly, the hypsometric equation is used to calculate the small difference in pressure between readings:

$P_{i+1}=P_{i} e^{\frac{z_{1}-z_{2}}{a T}}$
Hence, starting at the ground with $P_{0}$, calculate $P_{1}$, the pressure at the next level up, using mean $T$ between levels. Repeat for all levels to get $P(z)$. Potential temperature conversion is then calculated from pressure.

\section{References}

Albert, M. R.: Effects of snow and firn ventilation on sublimation rates, 35, Ann. Glaciol., 52-56, 2002.

Albert, M. R., Grannas, A. M., Bottenheim, J., Shepson, P. B., and Perron, F. E.: Processes and properties of snow-air transfer in the high Arctic with application to interstitial ozone at Alert, Canada, Atmos. Environ., 36, 2779-2787, 2002.

Anderson, P. S., Mobbs, S. D., King, J. C., McConnell, I., and Rees, J. M.: A Microbarograph for Internal Gravity-Wave Studies in Antarctica, Antarct. Sci., 4, 241-248, 1992.

Anderson, P. S.: Fine-scale structure observed in a stable atmospheric boundary layer by Sodar and kite-borne tethersonde, Bound.-Lay. Meterol., 107, 323-351, 2003.

Anderson, P. S., Ladkin, R. S., and Renfrew, I. A.: An autonomous Doppler sodar wind profiling system, J. Atmos. Ocean. Tech., 22, 1309-1325, 2005.

Anderson, P. S. and Bauguitte, S.: Behaviour of Tracer Diffusion in Simple Atmospheric Boundary Layer Models, Atmos. Chem. Phys. Discuss., 6, 13 111-13 138, 2006.

Arimoto, R., Zeng, T., Davis, D., Wang, Y., Khaing, H., Nesbit, C., and Huey, G.: Concentrations and Sources of Aerosol Ions and Trace Elements during ANTCI-2003, Atmos. Environ., ANTCI 2003 Special Issue, 42, 12, 2864-2876, doi:10.1016/j.atmosenv.2007.05.054, 2008.

Baas, P., J., S. G., Wiel, B. J. H. v. d., and Holtslag, A. A. M.: Exploring Self-Correlation in Flux-Gradient Relationships for Stably Stratified Conditions, J. Atmos. Sci., 63, 3045-3054, 2006.

Bottenheim, J. W., Fuentes, J. D., Tarasick, D. W., and Anlauf, K. G.: Ozone in the Arctic lower troposphere during winter and spring 2000 (ALERT2000), Atmos. Environ., 36, 2535-2544, 2002.

Bottenheim, J. W., and Chan, E.: A trajectory study into the origin of spring time Arctic boundary layer ozone depletion, J. Geophys. Res.-Atmos., 111, D19301, doi:10.1029/2006JD007055, 2006.

Bowling, L. C., Pomeroy, J. W., and Lettenmaier, D. P.: Parameterization of blowing-snow sublimation in a macroscale hydrology model, J. Hydrometeorol., 5, 745-762, 2004.

Bromwich, D. H., Carrascoa, J. F., and Stearns, C. R.: Satellite Observations of Katabatic-Wind Propagation for Great Distances across the Ross Ice Shelf, Mon. Weather Rev., 120, 1940-1949, 1992.

Carroll, J. J.: On The Determinants of the near-surface temperature regime on the South Polar Plateau, 89, 4941-4952, 1984.

Cohen, L., Helmig, D., Neff, W. D., Grachev, A. A., and Fairall, C. W.: Boundary-layer dynamics and its influence on atmospheric chemistry at Summit, Greenland, Atmos. Environ., 41, 50445060, 2007.

Culf, A. D.: Acoustic Sounding of the Atmospheric Boundary Layer at Halley, Antarctica, Antarct. Sci., 1, 363-372, 1989.

Cullen, N. J. and Steffen, K.: Unstable near-surface boundary conditions in summer on top of the Greenland ice sheet, Geophys. 
Res. Lett., 28, 4491-4493, 2001.

Cullen, N. J., Steffen, K., and Blanken, P. D.: Nonstationarity of turbulent heat fluxes at Summit, Greenland, Bound.-Lay. Meterol., 122, 439-455, 2007.

Cunningham, J. and Waddington, E. D.: Air-Flow and Dry Deposition of Non-Sea Salt Sulfate in Polar Firn - Paleoclimatic Implications, Atmos. Environ., Part a-General Topics, 27, 2943-2956, 1993.

Cuxart, J., Holtslag, A. A. M., Beare, R. J., Bazile, E., Beljaars, A., Cheng, A., Conangla, L., Ek, M., Freedman, F., Hamdi, R., Kerstein, A., Kitagawa, H., Lenderink, G., Lewellen, D., Mailhot, J., Mauritsen, T., Perov, V., Schayes, G., Steeneveld, G. J., Svensson, G., Taylor, P., Weng, W., Wunsch, S., and Xu, K. M.: Single-column model intercomparison for a stably stratified atmospheric boundary layer, Bound.-Lay. Meterol., 118, 273-303, 2006.

Davis, D., Nowak, J. B., Chen, G., Buhr, M., Arimoto, R., Hogan, A., Eisele, F., Mauldin, L., Tanner, D., Shetter, R., Lefer, B., and McMurry, P.: Unexpected high levels of NO observed at South Pole, Geophys. Res. Lett., 28, 3625-3628, 2001.

Davis, D., Chen, G., Buhr, M., Crawford, J., Lenschow, D., Lefer, B., Shetter, R., Eisele, F., Mauldin, L., and Hogan, A.: South Pole $\mathrm{NO}_{\mathrm{x}}$ chemistry: an assessment of factors controlling variability and absolute levels, Atmos. Environ., 38, 5375-5388, 2004a.

Davis, D., Eisele, F., Chen, G., Crawford, J., Huey, G., Tanner, D., Slusher, D., Mauldin, L., Oncley, S., Lenschow, D., Semmer, S., Shetter, R., Lefer, B., Arimoto, R., Hogan, A., Grube, P., Lazzara, M., Bandy, A., Thornton, D., Berresheim, H., Bingemer, H., Hutterli, M., McConnell, J., Bales, R., Dibb, J., Buhr, M., Park, J., McMurry, P., Swanson, A., Meinardi, S., and Blake, D.: An overview of ISCAT 2000, Atmos. Environ., 38, 5363-5373, 2004b.

Dibb, J. E., and Jaffrezo, J. L.: Air-snow exchange investigations at Summit, Greenland: An overview, J. Geophys. Res.-Oceans, 102, 26795-26807, 1997.

Dibb, J. E., Albert, M., Courville, Z., Anastasio, C., Galbavy, E. S., Atlas, E., Beyersdorf, A. J., Blake, D. R., Meinardi, S., Rowland, F. S., Swanson, A. L., Blake, N. J., Bocquet, F., Cohen, L., Helmig, D., Burkhart, J. F., Frey, M. M., Friel, D. K., Hutterli, M. A., Chen, G., Conway, T. J., and Oltrnans, S. J.: An overview of air-snow exchange at Summit, Greenland: Recent experiments and findings, Atmos. Environ., 41, 4995-5006, 2007.

Drue, C., and Heinemann, G.: Characteristics of intermittent turbulence in the upper stable boundary layer over Greenland, Bound.Lay. Meterol., 124, 361-381, 2007.

Ekman, V. W.: On the Influence of the Earth's Rotation on OceanCurrents, Arkiv For Matematik, Atronomi OCH Fysik, Band 2, 1-53, 1905.

Forrer, J., and Rotach, M. W.: On the turbulence structure in the stable boundary layer over the Greenland ice sheet, Bound.-Lay. Meterol., 85, 111-136, 1997.

Fotiadi, A., Lohou, F., Druilhet, A., Serça, D., Said, F., Laville, P., and Brut, A.: Methodological Development of the Conditional Sampling Method. Part II: Quality Control Criteria of Relaxed Eddy Accumulation Flux Measurements, Bound.-Lay. Meterol., 117, 577-603, 2005.

Helmig, D., Boulter, J., David, D., Birks, J. W., Cullen, N. J., Steffen, K., Johnson, B. J., and Oltmans, S. J.: Ozone and meteoro- logical boundary-layer conditions at Summit, Greenland, during 3-21 June 2000, Atmos. Environ., 36, 2595-2608, 2002.

Helmig, D., Johnson, B., Oltmans, S. J., Neff, W. D., Eisele, F. and Davis, D.: Elevated ozone in the boundary layer at the South Pole, Atmos. Environ., ANTCI 2003 Special Issue, 42, 12, 2788 2803, doi:10.1016/j.atmosenv.2006.12.032, 2008a.

Helmig, D., Warshawsky, M., Johnson, B., Buhr, M., Eisele, F., and Davis, D.: Nitric oxide in the boundary layer at the South Pole during the 2003 Antarctic Tropospheric Chemistry Investigation, Atmos. Environ., ANTCI 2003 Special Issue, 42, 12, 2817-2830, doi:10.1016/j.atmosenv.2007.03.061, 2008.

Hoch, S. W., Calanca, P., Philipona, R., and Ohmura, A.: Yearround observation of longwave radiative flux divergence in Greenland, J. Appl. Meteorol. Clim., 46, 1469-1479, 2007.

Holtslag, B.: Preface - GEWEX atmospheric boundary-layer study (GABLS) on stable boundary layers, Bound.-Lay. Meterol., 118, 243-246, 2006.

Horii, C. V., Munger, J. W., Wofsy, S. C., Zahniser, M., Nelson, D., and McManus, J. B.: Atmospheric reactive nitrogen concentration and flux budgets at a Northeastern US forest site, Agr. Forest Meteorol., 136, 159-174, 2006.

Houghton, J. T.: The Physics of Atmospheres, Second Edition ed., Cambridge University Press, pp. 129-130, 1986.

Jacobi, H. W., Weller, R., Jones, A. E., Anderson, P. S., and Schrems, O.: Peroxyacetyl nitrate (PAN) concentrations in the Antarctic troposphere measured during the photochemical experiment at Neumayer (PEAN'99), Atmos. Environ., 34, 52355247, 2000.

Jones, A. E., Weller, R., Anderson, P. S., Jacobi, H. W., Wolff, E. W., Schrems, O., and Miller, H.: Measurements of $\mathrm{NO}_{\mathrm{x}}$ emissions from the Antarctic snowpack, Geophys. Res. Lett., 28, 1499-1502, 2001.

Jones, A. E., Anderson, P. S., Wolff, E. W., Turner, J., Rankin, A. M., and Colwell, S. R.: A role for newly forming sea ice in springtime polar tropospheric ozone loss? Observational evidence from Halley station, Antarctica, J. Geophys. Res.-Atmos., 111, doi:10.1029/2005JD006566, 2006.

Jones, A. E., Anderson, P. S., and Roscoe, H. K.: Boundary layer structure and ozone loss in coastal Antarctica-classic and novel views, EGU, UGU08-A-02533, 2008.

Jones, A. E., Wolff, E. W., Salmon, R. A., Bauguitte, S. J.-B., Roscoe, H. K., Anderson, P. S., Ames, D., Clemitshaw, K., Z., F., Bloss, W. J., Lee, J. D., Heard, D. E., Jackson, A., Walker, S., Lewis, A., K., R., Hamer, P., E., S. D., Plane, J., Mills, G., Saiz-Lopez, A., Sturges, W., and Worton, D.: Chemistry of the Antarctic Boundary Layer and the Interface with Snow: An overview of the CHABLIS campaign, Atmos. Chem. Phys. Discuss., 8, 5137-5181, 2008, http://www.atmos-chem-phys-discuss.net/8/5137/2008/.

Kahl, J. D.: Characteristics Of The Low-Level Temperature Inversion Along The Alaskan Arctic Coast, Int. J. Climatol., 10, 537548, 1990.

Kerstein, A. R. and Wunsch, S.: Simulation of a stably stratified atmospheric boundary layer using one-dimensional turbulence, Bound.-Lay. Meterol., 118, 325-356, 2006.

King, J. C. and Anderson, P. S.: Heat and Water-Vapor Fluxes and Scalar Roughness Lengths over an Antarctic Ice Shelf, Bound.Lay. Meterol., 69, 101-121, 1994.

King, J. C., Argentini, S. A., and Anderson, P. S.: Contrasts be- 
tween the summertime surface energy balance and boundary layer structure at Dome C and Halley stations, Antarctica, J. Geophys. Res.-Atmos., 111, doi:10.1029/2005JD006130, 2006.

Lee, X., Massman, W., and Law, B.: Handbook of Micrometeorology, Kluwer Academic Publishers, Dordrecht, 2004.

Mahrt, L.: Stratified atmospheric boundary layers, Bound.-Lay. Meterol., 90, 375-396, 1999.

Mahrt, L., and Vickers, D.: Extremely weak mixing in stable conditions, Bound.-Lay. Meterol., 119, 19-39, 2006.

Mann, G. W., Anderson, P. S., and Mobbs, S. D.: Profile measurements of blowing snow at Halley, Antarctica, J. Geophys. Res.Atmos., 105, 24 491-24 508, 2000.

McKeon, B. J., and Morrison, J. F.: Asymptotic scaling in turbulent pipe flow, Philosophical Transactions of the Royal Society, London Series, 365, 771-787, doi:10.1098/rsta.2006.1945, 2007.

Neff, W. D.: Boundary-Layer Research at South-Pole Station Using Acoustic Remote-Sensing, Antarct. J. US, 13, 179-181, 1978.

Neff, W. D.: An observational and numerical study of the atmospheric boundary layer overlying the east Antarctic ice sheet, Astrogeophysics, University of Colorado, Boulder, 272 pp., 1980.

Neff, W. D., and Coulter, R. L.: Acoustic Remote Sensing, in: Probing the Atmospheric Boundary Layer, edited by: Lenshow, D. H., American Meteorological Society, Boston, 201-236, 1985.

Neff, W. D.: Decadal time scale trends and variability in the tropospheric circulation over the South Pole, J. Geophys. Res.-Atmos., 104, 27 217-27 251, 1999.

Neff, W. D., Helmig, D., Grachev, A., and Davis, D.: A study of boundary Layer behavior associated with high NO concentrations at the South Pole using a minisodar, tethered balloon, and sonic anemometer, Atmos. Environ., ANTCI 2003 Special Issue, 42, 12, 2762-2779, doi:10.1016/j.atmosenv.2007.01.033, 2008.

Neumann, T. A., and Waddington, E. D.: Effects of firn ventilation on isotopic exchange, J. Glaciol., 50, 183-194, 2004.

Nieuwstadt, F. T. M.: Review of diffusion processes in the convective boundary layer, in: Buoyant Convection in Geophysical Flows, edited by: Plate, E. J., 371-399, 1998.

Oerlemans, J. and Tijm-Reijmer, C. H.: Automatic Weather Stations on Glaciers, Institute for Marine and Atmospheric Research Utrecht, Utrecht University, The Netherlands, 2004.

Oltmans, S. J.: Surface Ozone Measurements In Clean-Air, J. Geophys. Res.-Oc. Atm., 86, 1174-1180, 1981.

Oncley, S. P., Buhr, M., Lenschow, D. H., Davis, D., and Semmer, S. R.: Observations of summertime NO fluxes and boundarylayer height at the South Pole during ISCAT 2000 using scalar similarity, Atmos. Environ., 38, 5389-5398, 2004.

Pomeroy, J. W. and Essery, R. L. H.: Turbulent fluxes during blowing snow: field tests of model sublimation predictions, Hydrol. Process., 13, 2963-2975, 1999.

Rankin, A. M., and Wolff, E. W.: Aerosol Profiling Using a Tethered Balloon in Coastal Antarctica, J. Atmos. Ocean. Tech., 19, 1978-1985, 2002.

Saiz-Lopez, A., Mahajan, A. S., Plane J. M. C., Anderson, P. S., Bauguitte, S. J.-B., Jones, A. E., Roscoe, H. K., and Salmon, R. A.: On the vertical distribution of boundary layer halogens over coastal Antarctica, Atmos. Chem. Phys., 8, 887-900, 2008, http://www.atmos-chem-phys.net/8/887/2008/.

Schnell, R. C., Barry, R. G., Miles, M. W., Andreas, E. L., Radke, L. F., Brock, C. A., McCormick, M. P., and Moore, J. L.: Lidar Detection Of Leads In Arctic Sea Ice, Nature, 339, 530-532,
1989.

Schumann, U.: Large-eddy simulation of turbulent diffusion with chemical reactions in the convective boundary layer, Atmos. Environ., 23, 1713-1727, 1989.

Serreze, M. C., Maslanik, J. A., Rehder, M. C., Schnell, R. C., Kahl, J. D., and Andreas, E. L.: Theoretical Heights Of Buoyant Convection Above Open Leads In The Winter Arctic Pack Ice Cover, J. Geophys. Res.-Oceans, 97, 9411-9422, 1992.

Shepson, P., Matrai, P., Barrie, L., and Bottenheim, J. W.: OceanAtmosphere-Sea Ice-Snowpack Interactions in the Arctic and Global Change, EOS, 84, 349, 2003.

Steeneveld, G. J., Van de Wiel, B. J. H., and Holtslag, A. A. M.: Modelling the arctic stable boundary layer and its coupling to the surface, Bound.-Lay. Meterol., 118, 357-378, 2006.

Stull, R. B.: An Introduction to Boundary Layer Meteorology, Kluwer Academic Publishers, Dordrecht, Dordrecht, 666 pp., 1988.

Stull, R. B.: Meteorology for Scientists and Engineers, Second Edition ed., Gary Garlson, 2000.

Tarasick, D. W., and Bottenheim, J. W.: Surface ozone depletion episodes in the Arctic and Antarctic from historical ozonesonde records, Atmos. Chem. Phys., 2, 197-205, 2002, http://www.atmos-chem-phys.net/2/197/2002/.

Turnipseed, A. A., Huey, L. G., Nemitz, E., Stickel, R., Higgs, J., Tanner, D. J., Slusher, D. L., Sparks, J. P., Flocke, F., and Guenther, A.: Eddy covariance fluxes of peroxyacetyl nitrates (PANs) and $\mathrm{NO}_{\mathrm{y}}$ to a coniferous forest, J. Geophys. Res.-Atmos., 111 (D9), 2006.

Udisti, R., Becagli, S., Benassai, S., Castellano, E., Fattori, I., Innocenti, M., Migliori, A., and Traversi, R.: Atmosphere-snow interaction by a comparison between aerosol and uppermost snowlayers composition at Dome C, East Antarctica, 39, 2005, Ann. Glaciol., 53-61, 2004.

Ulanovsky, A. E., Yushkov, V. A., Sitnikov, N. M., and Ravengnani, F.: The FOZAN-II Fast-Response Chemiluminescent Airborne Ozone Analyzer, Instruments and Experimental Techniques, 44, 249-256, 2001.

van den Broeke, M. R., van As, D., Reijmer, C. H., and van de Wal, R.: Sensible heat exchange at the Antarctic snow surface: a study with automatic weather stations, Int. J. Climatol., 25, 1081-1101, 2005.

Vickers, D., and Mahrt, L.: Evaluating formulations of stable boundary layer height, J. Appl. Meteorol., 43, 1736-1749, 2004.

Wang, Y., Choi, Y., Zeng, T., Davis, D., Buhr, M., Huey, G., and Neff, W. D.: Assessing the photochemical impact of snow $\mathrm{NO}_{\mathrm{X}}$ emissions over Antarctica during ANTCI 2003, Atmos. Environ., 41, 3944-3958, doi:10.1016/j.atmosenv.2007.07.062, 2008.

Zilitinkevich, S. and Baklanov, A.: Calculation of the height of the stable boundary layer in practical applications, Bound.-Lay. Meterol., 105, 389-409, 2002.

Zilitinkevich, S., Baklanov, A., Rost, J., Smedman, A. S., Lykosov, V., and Calanca, P.: Diagnostic and prognostic equations for the depth of the stably stratified Ekman boundary layer, Q. J. Roy Meteor. Soc., 128, 25-46, 2002. 